Article

\title{
Spatiotemporal analysis of soil moisture variation in the Jiangsu Water Supply Area of the South-to-North Water Diversion using ESA CCI data
}

\author{
Yue Wang ${ }^{1,2}$, Jianjun Cao ${ }^{1,3,4 *}$, Yongjuan Liu ${ }^{1}$, Ying Zhu ${ }^{1}$, Xuan Fang ${ }^{1,3}$, Qing Huang ${ }^{1}$ and Wolfgang Wagner ${ }^{4}$ \\ 1 School of Environmental Science, Nanjing Xiaozhuang University, Nanjing 211171, China; \\ liu743@njxzc.edu.cn (Y.L.); zhuying@njxzc.edu.cn (Y.Z.); xuanfang@njxzc.edu.cn (X.F.); \\ huangqing@njxzc.edu.cn (Q.H.) \\ 2 College of Marine Sciences, Shanghai Ocean University, Shanghai 201306, China; \\ m210200622@st.shou.edu.cn (Y.W.) \\ 3 School of Geography Science/ Key Laboratory of Virtual Geographic Environment of Ministry of Education, \\ Nanjing Normal University, Nanjing 210023, China; jjcao@njnu.edu.cn (J.C.); \\ 4 Department of Geodesy and Geoinformation, Vienna University of Technology, Vienna 1040, Austria; \\ wolfgang.wagner@geo.tuwien.ac.at (W.W.) \\ * Correspondence: jjcao@njnu.edu.cn; Tel.:+86-1-364-517-2697
}

\begin{abstract}
The South-to-North Water Transfer Jiangsu Water Supply Area (JWSA) is a mega interbasin water transfer area (water source) that provides water resources from JiangHuai, combines drainage and flooding management, and regulates nearby rivers and lakes. Analyzing the spatiotemporal soil moisture dynamics in the area will inform agricultural drought and flood disaster assessment and early warning studies. Therefore, we evaluated the quality of European Space Agency Climate Change Initiative Soil moisture (ESA CCI_SM) data in the South-North Water Transfer JWSA. Then, we used ensemble empirical modal decomposition, Mann-Kendall tests, and regression analysis to study the spatiotemporal variation in soil moisture for the past 29 years. The CCI _SM data showed a high correlation with local soil measurements at nine sites. We then analyzed the CCI_SM data from three pumping stations (the Gaogang, Hongze, and Liushan stations) in the South-North Water Transfer JWSA. These stations had similar periodic characteristics of soil moisture, with significant periodic fluctuations around $3.1 \mathrm{~d}$. The overall soil moisture at the three typical pumping stations showed an increasing trend. We then investigated whether there were abrupt soil moisture changes at each station. The spatial distribution of soil moisture in the South-North Water Transfer JWSA was characterized by "dry north and wet south", with higher soil moisture in winter, followed by autumn, and low soil moisture in spring and summer. Although the linear trend of soil moisture in the South-North Water Transfer JWSA varied in significance, the overall soil moisture in the JWSA has increased over the past 29 years. The areas with significantly enhanced soil moisture are mainly distributed in the Yangzhou and Huai'an areas in the southeastern part of the study area. The areas with significantly decreased soil moisture are small in size and mainly located in northern Xuzhou.
\end{abstract}

Keywords: ESA CCI; soil moisture; EEMD; Mann-Kendall; temporal and spatial variation; Jiangsu water supply area (JWSA)

\section{Introduction}

Soil moisture, which is also referred to as soil water content, is the volumetric water content in soil. It plays an important role in hydrological and meteorological processes, and acts as a major factor controlling precipitation runoff and infiltration [1-6]. Soil moisture also has a significant impact on the net radiation to latent and sensible heat ratios and the precipitation to infiltration, runoff, and evaporation ratios [7-15]. Furthermore, soil moisture is a key state variable in the Earth's climate system that helps regulate the 
exchange of water, energy, and carbon between the surface of the Earth and the atmosphere [16-18]. Soil moisture plays a critical role in various processes and feedback loops [19-20]. Therefore, an accurate and thorough understanding of soil moisture status and its spatial and temporal dynamics have significant research value for hydrological simulations, crop growth and development decision-making, and soil drought and flood monitoring.

Many technologies have been developed to measure soil moisture with ground instruments, such as gravimetric methods[21-22], time-domain reflectometers[23-24], capacitance sensors[25-26], neutron detectors[27-29], resistivity measurements[30-32], heat-pulse sensors[33-34], and fiber optic sensors[35-36]. With these technologies, highresolution spatio-temporal measurements of soil moisture can be obtained at the point scale. Their advantages include ease of installation, dependability, and the ability to detect soil moisture at different depths. Measurement results from these technologies are typically considered as the "real measured value" of soil moisture, which is important for establishing unified databases for long-term soil moisture measurement networks. Due to the high spatial heterogeneity of soil moisture at different spatial scales, the values measured using a point scale cannot adequately represent the soil moisture in neighboring areas [37-40]. Thus, the measurements are only appropriate for obtaining local, small-scale soil moisture. To obtain large-scale soil moisture data in a given region, geostatistical techniques can be employed to extrapolate point-scale soil moisture to a larger regional scale [41-44]. However, the spatial characteristics of the measured soil moisture network are not suitable for constructing a spatial distribution of soil moisture at a regional scale. Moreover, on surfaces with high spatial heterogeneity, extrapolating point-scale measurements to large-scale spaces is complicated and time-consuming [45-48]. In fact, dense soil moisture observation networks have not yet been established for many areas. Therefore, despite the emergence of new measurement technologies for soil moisture, such as the cosmic-ray soil moisture observation system (COSMOS) [49-52] and the global positioning system (GPS) [53-55] , it remains challenging to utilize ground instruments to quantify the spatiotemporal distributions of soil moisture on a regional and larger scale.

Satellite research and application institutions, both domestic and international, have launched their own global soil moisture remote sensing products, such as the Advanced Microwave Scanning Radiometer (AMSR-E) [56-59], Advanced Microwave Scanning Radiometer 2 (AMSR2) [60-61], and Soil Moisture Active Passive (SMAP) [62-64] satellites, the European Space Agency's (ESA) Soil Moisture and Ocean Salinity (SMOS) [65-67] , Fengyun-3 (FY-3B) [68-69] , ands Sentinel-1 satellite, and others satellites used in the Earth Observation System. Several studies have also evaluated the quality of soil moisture measurements obtained by satellite remote sensing in various regions [70-74]. These studies show that although these remote sensing products have some errors, the results are reasonably accurate when they are used to explore the spatiotemporal variations in soil moisture on the Earth's surface,. Due to the constraints of Earth's period, time series, and satellite orbits, the promotion and use of soil moisture data measurements for climate change, drought, and flood monitoring have been limited.

In 2010, the ESA launched a project on climate change. The overall objective of the project is to develop a set of comprehensive and consistent long-term global soil moisture data using active and passive microwave sensors. This dataset will enable long-term dynamic analysis of soil moisture variations [75-79]. At present, the ESA CCI SM data are primarily used for quality evaluation and drought assessment in northern China [80-85]. However, these data are rarely applied to southern China.

The South-to-North Water Transfer Jiangsu Water Supply Zone is a mega inter-basin water transfer area (water source) that provides the benefits of Jianghuai water resources, combines drainage and flood (waterlogging) relief, and regulates rivers and lakes [86-93]. The Jiangsu Water Supply Zone has vertical and horizontal rivers, lakes, and streams which together form a relatively independent water source and an important agricultural 
production area. Due to the increasing demand for science and technology in the Jiangsu Water Supply Zone to inform agricultural production development and water resource management, meteorological decision-making services have become increasingly important, particularly in disaster decision-making pertaining to soil drought and floods. By tracking regional soil moisture levels and drought and flood conditions in real time, it is possible to analyze the impacts of crop growth and south-to-north water transfer on water resources in a timely manner. By analyzing and monitoring the spatial and temporal evolution of soil moisture using ESA CCI data, it will be possible to further explore ecological changes in the South-to-North Water Transfer Jiangsu Water Supply Zone, thereby providing a decision-making framework to assess and provide early warning of agricultural drought and flood disasters. Therefore, the South-to-North Water Transfer Jiangsu Water Supply Zone was analyzed in this study. The validity of the ESA CCI soil moisture (CCI_SM) data was verified by data collected on-site. We analyzed the spatiotemporal variations of soil moisture in the study area over the past 29 years. Our study will facilitate the use of the ESA soil moisture data set for assessing ecological changes in southern China.

\section{Materials and methods}

\subsection{Study area overview}

The South-to-North Water Transfer Jiangsu Water Supply Zone is located in the lower reaches of the Yangtze and the Huai rivers. It forms a vital part of the Yangtze River Delta and encompasses five prefecture-level city administrative regions, including Yangzhou, Huai'an, Suqian, Xuzhou, and Lianyungang. This area covers a land mass approximately between $116^{\circ} 22^{\prime}-119^{\circ} 48^{\prime} \mathrm{E}$ and $32^{\circ} 14^{\prime}-35^{\circ} 7^{\prime} \mathrm{N}$. It contais flat terrain, a dense network of rivers, and is characterized by a temperate subtropical climate. The average annual temperature is approximately $15{ }^{\circ} \mathrm{C}$ and the average annual rainfall is approximately $950 \mathrm{~mm}$. The Jiangsu Water Supply Zone has diverse soil types resulting from its climate, topography and soil parent material. In the north, most of the soil is loamy clay. In the south, most of the soil is moderate-viscosity sandy loam, largely due to the influence of the Yangtze River. Because of the climate conditions and unique geographical location of the Jiangsu Water Supply Zone, various vegetation types, including temperate deciduous forests and subtropical evergreen forests are located within the area (Figure 1). 


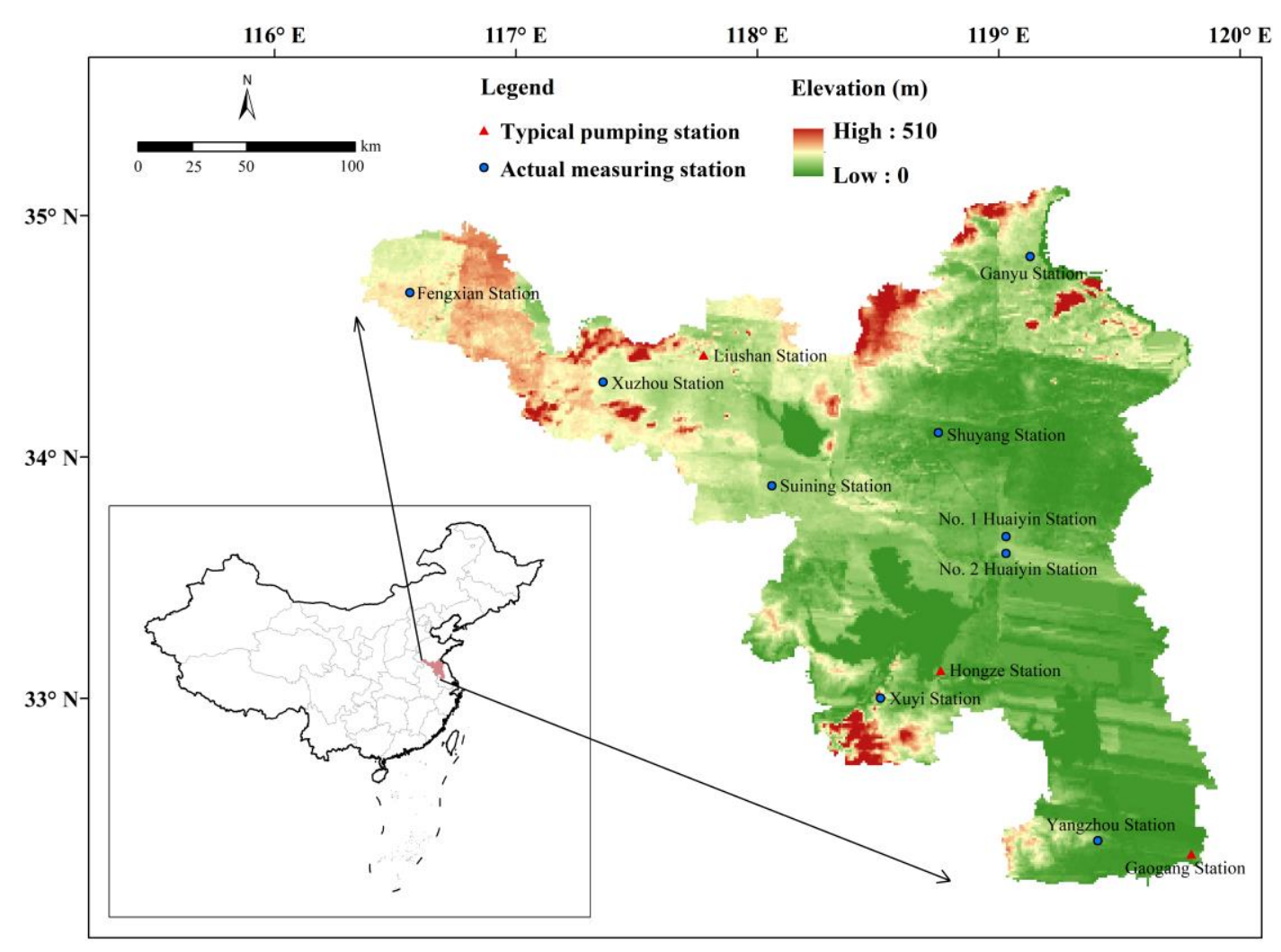

Figure 1 Study area and station distribution

\subsection{ESA CCI_SM dataset}

The ESA CCI_SM is a set of soil moisture data comprising the active, passive, and active-passive fusion of soil moisture with a spatial resolution of $0.25^{\circ}$ and a temporal resolution of $1 \mathrm{~d}$. AMI-WS and ASCAT were used as data sources for active microwave products. These data were inverted using the WARP v5.5 inversion model developed by the Vienna University of Technology. Then, the data were integrated to produce microwave soil moisture data [relative moisture content (\%)] from 1991-2013. SMMR, SSM/I, TMI, AMSR-E, WindSat, and AMSR-2 data were used for passive microwave products. These data were inverted using the LPRM v5 inversion model jointly developed by Vrije Universiteit Amsterdam and NASA. Then, the data were integrated to produce passive microwave soil moisture data [volumetric water content $\left(\mathrm{m}^{3} / \mathrm{m}^{3}\right)$ ] from 1978-2019. The fusion soil moisture dataset was created by merging the active and passive data sources outlined above [94]. The time range of this dataset is 1978-2019 and the unit is volumetric water content $\left(\mathrm{m}^{3} / \mathrm{m}^{3}\right)$. The quality of the three types of soil moisture products mentioned above was evaluated previously. Their results indicate that the fusion soil moisture data product has higher data quality than that before the fusion. Thus, the ESA CCI_SM data after active and passive fusion were used to assess the remote sensing data quality and to analyze the spatiotemporal variations of soil moisture in the South-toNorth Water Transfer Jiangsu Water Supply Zone.

The original CCI data was downloaded in NETCDF format based on the CCI active and passive fusion soil moisture data from 1991 to 2019. First, a Python program was written to convert the data to TIF format to facilitate data analysis. The data has a temporal resolution of one scene per day. Following the conversion, an IDL program was written to divice the study area into batches. Since the measured data used a ten-day time scale, the CCI remote sensing data were averaged over ten days to facilitate quality assessment. 
A total of 1044 scenes were extracted after processing, with $12 \times 14$ grids per scene. The grid values where stations are located were extracted. The soil moisture data were then compared to measurements obtained at the stations. In total, 1500 valid measurements were collected from 9 stations.

\subsection{Measured data}

We used 10-cm relative soil moisture data provided by the China Meteorological Data Center. The time scale is 10 days, the unit is relative soil moisture (\%), and the time period is from 1991 to 2013. There are 9 stations in the study area (Figure 1). It should be noted that the measured data and the CCI_SM data have different units of measurement. To compare the two datasets, it was necessary to unify the dimensions and convert the measured data. The relative soil moisture as converted into soil volumetric water content as follows [95]:

$$
q=r \times f_{c} \times p
$$

Where $q$ is the soil volumetric water content, $r$ is the relative soil moisture, $f_{c}$ is the field water capacity, and $p$ is the soil bulk density $\left(\mathrm{g} / \mathrm{cm}^{3}\right)$ [96].

\subsection{Data quality evaluation}

Once the measured and CCI data dimensions were unified, statistical indices were used to calculate the Pearson correlation coefficient (R) to determine the degree of correlation. The difference between the two datasets was measured by the root mean square error (RMSE) and mean absolute error (MAE). The corresponding formulas are as follows:

$$
\begin{aligned}
& R=\frac{\sum_{i=1}^{n}\left(s_{i}-\bar{s}\right)\left(g_{i}-\bar{g}\right)}{\sqrt{\sum_{i=1}^{n}\left(s_{i}-\bar{s}\right)^{2} \sum_{i=1}^{n}\left(g_{i}-\bar{g}\right)^{2}}} \\
& R M S E=\sqrt{\frac{1}{n} \sum_{i=1}^{n}\left(s_{i}-g_{i}\right)^{2}} \\
& M A E=\sqrt{\frac{1}{n} \sum_{i=1}^{n}\left|s_{i}-g_{i}\right|}
\end{aligned}
$$

Where: $\boldsymbol{g}_{\boldsymbol{i}}$ and $\boldsymbol{s}_{\boldsymbol{i}}$ represent the soil moisture measured at the station and the CCI remote sensing soil moisture during the $\boldsymbol{i}$ th period, respectively. $\overline{\boldsymbol{g}}$ and $\overline{\boldsymbol{s}}$ represent the average soil moisture measured at the station and the average CCI remote sensing soil moisture, respectively.

\subsection{Ensemble empirical mode decomposition (EEMD)}


$\mathrm{Wu}$ and Huang proposed the Ensemble Empirical Mode Decomposition (EEMD) algorithm, which is a signal analysis algorithm applicable to nonlinear and nonstationary sequences[97]. This method overcomes the deficiencies of Empirical Mode Decomposition (EMD) such as "modal aliasing" and "end effects" [98]. Based on the statistical characteristics of noise and the principle of EMD scale separation, auxiliary Gaussian white noise as introduced into the original signal. Then, an EMD decomposition of the noise-added signal as performed and the complex signal was decomposed into several independent orthogonal intrinsic mode functions (IMFs) and a residual standard error component (RSE). Because the white noise spectrum is uniformly distributed, it is canceled after ensemble averaging. The result of the ensemble average was used as the final IMF component. The specific process is as follows:

Gaussian white noise $\boldsymbol{n}_{\boldsymbol{k}}(\boldsymbol{t})$ is introduced into the original signal $\boldsymbol{x}(\boldsymbol{t})$, that is:

$$
X_{k}(t)=x(t)+n_{k}(t), k=1,2, \ldots, M
$$

Where $\boldsymbol{n}_{\boldsymbol{k}}(\boldsymbol{t})$ is the $\boldsymbol{k}$ th white noise sequence and $\boldsymbol{X}_{\boldsymbol{k}}(\boldsymbol{t})$ is the signal after adding the kth noise.

After performing an EMD decomposition on $\boldsymbol{X}_{\boldsymbol{k}}(\boldsymbol{t})$, the IMF component obtained is denoted as $\boldsymbol{c}_{\boldsymbol{i}, \boldsymbol{k}}(\boldsymbol{t})$ and the residual component is denoted as $\boldsymbol{r}_{\boldsymbol{k}}(\boldsymbol{t})$.

$$
x_{k}(t)=\sum_{i=1}^{n} c_{i, k}(t)+r_{k}(t)
$$

Where $\boldsymbol{c}_{\boldsymbol{i}, \boldsymbol{k}}(\boldsymbol{t})$ is the $\boldsymbol{i}$ th IMF component after adding the $\boldsymbol{k}$ th white noise and $\boldsymbol{r}_{\boldsymbol{k}}(\boldsymbol{t})$ is the residual component after adding the $\boldsymbol{k}$ th white noise.

Steps (2) and (3) are repeated until $\boldsymbol{k}=\boldsymbol{M}$ ( $\boldsymbol{M}$ is the overall average number of times).

The ensemble average of the decomposed IMF components was calculated to eliminate influences of noise:

$$
\begin{aligned}
& c_{s}(t)=\frac{1}{M} \sum_{i=1}^{M} c_{i, s}(t), i=1,2, \ldots, M ; s= \\
& 1,2, \ldots, S
\end{aligned}
$$

Where $\boldsymbol{c}_{\boldsymbol{s}}(\boldsymbol{t})$ is the EEMD decomposition result.

To determine whether the IMF component obtained by decomposition had physical significance, a significance test was performed as follows: 
Based on the Monte Carlo method, once the signal containing Gaussian white noise was decomposed by EEMD, the average energy spectral density (ESD) of the IMF component and the average period exhibited the following relationship:

$$
\ln \overline{\mathbf{E}}_{\mathbf{k}}+\ln \left\{\overline{\mathbf{T}}_{\mathbf{K}}\right\}_{a}=\mathbf{0}
$$

Where $\overline{\mathbf{E}}_{\mathbf{k}}$ is the average ESD of the $\boldsymbol{k}$ th IMF component and $\overline{\mathbf{T}}_{\mathbf{k}}$ is the average period of the $\boldsymbol{k}$ th IMF component. Theoretically, the relationship between the two can be expressed as a straight line with a slope of -1 . However, there are deviations in practical applications, so the relationship between the two can be expressed as follows:

$$
\ln \overline{\mathrm{E}}_{\mathrm{k}}=\ln \left\{\overline{\mathrm{T}}_{\mathrm{K}}\right\}_{a} \pm a \sqrt{\frac{2}{N e}}^{\ln \left(\frac{\left\{\overline{\mathrm{T}}_{\mathrm{K}}\right\}_{a}}{2}\right)}
$$

Where $\overline{\mathbf{E}}_{\mathbf{k}}$ is the average ESD, $\overline{\mathbf{T}}_{\mathbf{k}}$ is the average period, $\boldsymbol{N} \boldsymbol{e}$ is the degree of freedom, and $\boldsymbol{a}$ is the confidence level. When an IMF component is above the significance level, it indicates significant physical significance.

\subsection{Mann-Kendall method}

In this study, the Mann-Kendall (MK) test method [99] was used to analyze abrupt changes in soil moisture. The MK method is a non-parametric test that does not require data to follow a normal distribution. Individual outliers do not affect the analysis. The MK abrupt change test is based on the following general principle:

(1) Suppose there are $\boldsymbol{n}$ samples in the time series $\boldsymbol{x}$. The rank sequence is constructed as follows:

$$
S_{k}=\Sigma_{i=1}^{k} r_{i}, k=2,3, \ldots, n
$$

Where:

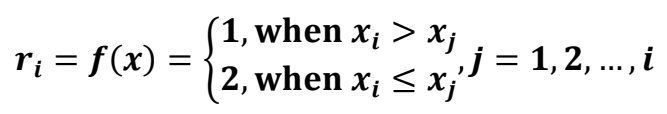

$\boldsymbol{S}_{\boldsymbol{k}}$ represents the cumulative sum, which is obtained by counting the number of instances where the $\boldsymbol{i}$ th value is greater than the $\boldsymbol{j}$ th value in the time series $\boldsymbol{x}$. 
(2) When $\boldsymbol{x}$ is a random independent time series, the following statistical quantity can be constructed:

$$
U F_{k}=\frac{S_{k}-E\left(S_{k}\right)}{\sqrt{\operatorname{Var}\left(S_{k}\right)}}, k=1,2, \ldots, n
$$

Where $\boldsymbol{U} \boldsymbol{F}_{1}=\mathbf{0}, \boldsymbol{E}\left(\boldsymbol{S}_{\boldsymbol{k}}\right)$ is the average of $\boldsymbol{S}_{\boldsymbol{k}}$, and $\operatorname{Var}\left(\boldsymbol{S}_{\boldsymbol{k}}\right)$ is the variance of $\boldsymbol{S}_{\boldsymbol{k}}$.

(3) Suppose that if the time series are continuously distributed and independent of one another, then:

$$
\begin{gathered}
E\left(S_{k}\right)=\frac{\mathbf{n}(\mathbf{n}+\mathbf{1})}{4} \\
\operatorname{Var}\left(S_{k}\right)=\frac{\mathbf{n}(\mathbf{n}-\mathbf{1})(2 \mathbf{n}+5)}{72}
\end{gathered}
$$

The normally distributed statistic $\boldsymbol{U} \boldsymbol{F}$ is constructed from the time series $\boldsymbol{x}$ and is tested for significance. The significance level is set at $\boldsymbol{\alpha}$. When $\left|\boldsymbol{U} \boldsymbol{F}_{\boldsymbol{i}}\right|>\boldsymbol{U}_{\boldsymbol{\alpha}}$, the time series $\boldsymbol{x}$ exhibits an obvious variation trend. By performing sample inversion on $\boldsymbol{x}$, a new time series can be obtained, that is, $\boldsymbol{x}_{\boldsymbol{n}}, \boldsymbol{x}_{\boldsymbol{n}-\mathbf{1}}, \ldots, \boldsymbol{x}_{\mathbf{1}}$. By applying the above operations to the new time series, a new rank sequence can be obtained, that is, $\boldsymbol{U B}_{\boldsymbol{k}}=-\mathbf{U F}_{\mathbf{k}}$, where $U B_{1}=0, k=n, n-1, \ldots, 1$.

The variation of a time series can be determined by analyzing the $\boldsymbol{U F}_{\boldsymbol{K}}$ and $\boldsymbol{U}_{\boldsymbol{k}}$ curves: $\boldsymbol{U}_{\boldsymbol{K}}>\mathbf{0}$ indicates an increasing trend and $\boldsymbol{U}_{\boldsymbol{K}}<\mathbf{0}$ indicates a decreasing trend. Given the significance level lines, if $\boldsymbol{U}_{\boldsymbol{k}}$ exceeds these lines, it indicates that there is a significant increasing or decreasing trend. If the two curves intersect between the significance level lines, the time corresponding to this point indicates the starting point of the abrupt change.

\subsection{Regression analysis}

Using the unary linear model and least square method, the slope of the CCI_SM data from 1991 to 2019 in the study area were fit pixel by pixel and the spatial variation of soil moisture in the study area was obtained. A comprehensive analysis of the soil moisture variation direction and rate in the study area was calculated as follows [100]:

$$
\theta_{\text {slope }}=\frac{n \times \sum_{i=1}^{n} i \times S M_{i}-\left(\sum_{i=1}^{n} i\right)\left(\sum_{i=1}^{n} S M_{i}\right)}{n \times \sum_{i=1}^{n} i^{2}-\left(\sum_{i=1}^{n} i\right)^{2}}
$$

Where $\boldsymbol{\theta}_{\text {slope }}$ represents the variation, $\boldsymbol{S M}_{\boldsymbol{i}}$ is the CCI_SM of the $\boldsymbol{i}$ th year, and $\boldsymbol{n}$ is the number of years being studied. If $\boldsymbol{\theta}_{\text {slope }}>0$, the soil moisture exhibits an upward trend. 
If $\boldsymbol{\theta}_{\text {slope }}<0$, the soil moisture exhibits a downward trend. The value of $\boldsymbol{\theta}_{\text {slope }}$ reflects the variation of the soil moisture.

F-tests were used to determine the significance of the variation [101] as follows:

$$
F=U \times \frac{n-2}{Q}
$$

Where $U=\sum_{i=1}^{n}\left(\widehat{y}_{i}-\bar{y}\right)^{2}$ is the error sum of squares; $Q=\sum_{i=1}^{n}\left(y_{i}-\widehat{y}_{i}\right)^{\mathbf{2}}$ is the regression sum of squares; $\boldsymbol{n}$ is the number of years being studied; $\boldsymbol{y}_{\boldsymbol{i}}$ the CCI_SM of the $\boldsymbol{i}$ th year; $\widehat{\boldsymbol{y}}_{\boldsymbol{i}}$ is its regressed value; and $\overline{\boldsymbol{y}}$ is the average soil moisture of the study period.

Based on the F-test results, the variation was divided into six levels (Table 1).

Table 1. Levels classified based on F-test results

\begin{tabular}{|c|c|c|c|c|c|c|c|}
\hline \multirow{2}{*}{ Condition } & \multirow{2}{*}{$\begin{array}{c}\text { Slope } \\
\text { P }\end{array}$} & \multicolumn{3}{|c|}{$<0$} & \multicolumn{3}{|c|}{$>0$} \\
\hline & & $\leq 0.01$ & $0.01<\mathrm{P} \leq 0.05$ & $P>0.05$ & $\leq 0.01$ & $0.01<\mathrm{P} \leq 0.05$ & $P>0.05$ \\
\hline $\begin{array}{l}\text { Test } \\
\text { result }\end{array}$ & $\begin{array}{l}\text { Soil moisture } \\
\text { variation } \\
\text { trend }\end{array}$ & $\begin{array}{l}\text { Extremely } \\
\text { significant } \\
\text { decrease }\end{array}$ & $\begin{array}{l}\text { Significant } \\
\text { decrease }\end{array}$ & $\begin{array}{c}\text { Non- } \\
\text { significant } \\
\text { decrease }\end{array}$ & $\begin{array}{l}\text { Extremely } \\
\text { significant } \\
\text { increase }\end{array}$ & $\begin{array}{l}\text { Significant } \\
\text { increase }\end{array}$ & $\begin{array}{l}\text { Non- } \\
\text { significant } \\
\text { increase }\end{array}$ \\
\hline
\end{tabular}

\section{Results}

\subsection{Verification of the CCI_SM data quality}

In Figure 2, a scatter plot of the soil moisture measured at 9 stations and the CCI_SM data is shown for the South-to-North Water Transfer Jiangsu Water Supply Zone from 1991 to 2013. We observed a high correlation between the measured values and the ESA CCI_SM (R=0.69). RMSE between the two was 0.036 and MAE is 0.029 , showing that the deviation between the remote sensing data and the measured data is reasonably small. These results suggest that remote sensing data may provide a rough indication of the true characteristics of soil moisture in the study area. 


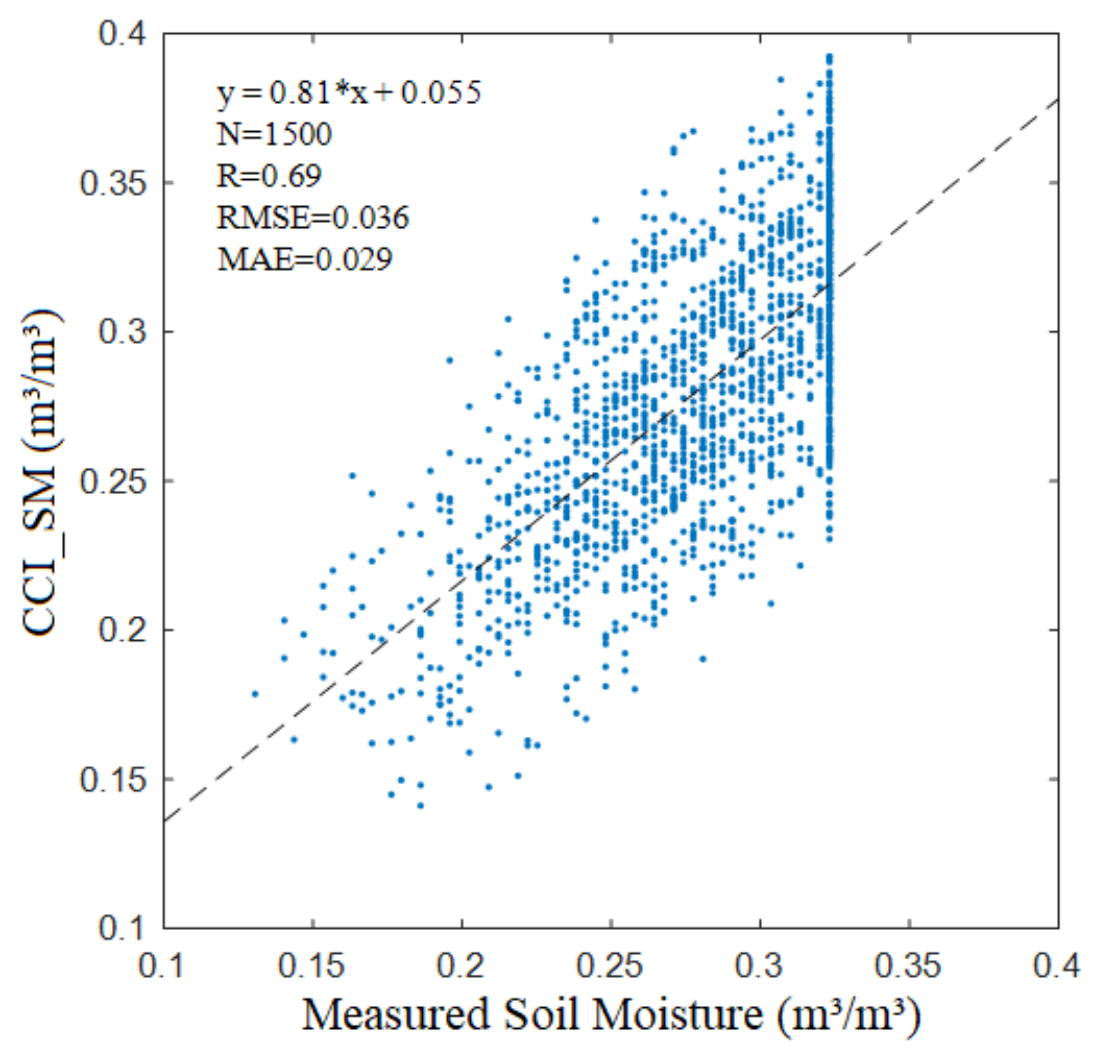

Figure 1 Scatter plot of the measured soil moisture and ESA CCI_SM in the study area during 1991-2013

The scatter plots of the measured soil moisture and the ESA CCI_SM by station from 1991 to 2013 are shown in Figure 3. The measured moisture and the ESA CCI_SM data exhibit good correlations at the Fengxian, Suining, Xuyi, and No. 1 Huaiyin Stations ( $R>$ 0.7). At the Shuyang, Ganyu, and No. 2 Huaiyin Stations, we observed R values between 0.6 and 0.7. However, at the Xuzhou and Yangzhou Stations, the correlations between the two datasets were relatively low. As indicated by the slopes $(<1)$ of the linear regression equations for the nine scatter plots, the CCI_SM data quality is lower than the measured value. Apart from the low spatial resolution of the CCI data, the uneven distribution of measuring stations, large differences in land cover patterns, non-uniform underlying surfaces, and inconsistent observation depth of soil may explain the error. For remote sensing of soil moisture using C-band and X-band microwaves, the representative depth is $0-2 \mathrm{~cm}$, while the recommended depth for using the L-band microwave is $0-5 \mathrm{~cm}$ [102]. However, the measured soil moisture data are soil volumetric water contents at a depth of $10 \mathrm{~cm}$. Also, since the measured data are an average value of soil moisture while satellite remote sensing can only detect the soil moisture at a given time point, there is a discrepancy in the timing of the two measurements. In particular, at Yangzhou Station in the south part of the study area, which is near the Yangtze River, soil moisture is significantly affected by rainfall, irrigation, and evaporation. The application of ESA CCI_SM products in this area is therefore restricted, resulting in an underestimation of surface soil moisture by ESA CCI_SM, especially after precipitation or irrigation. 
(a) Fengxian Station

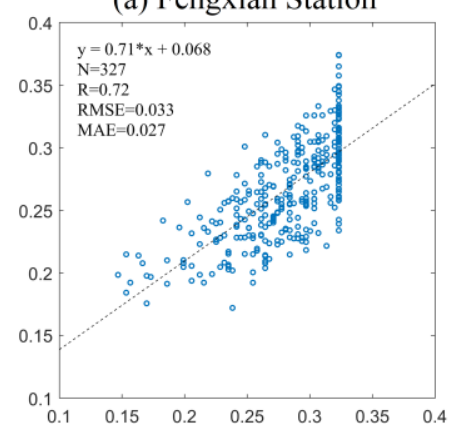

(d) Shuyang Station

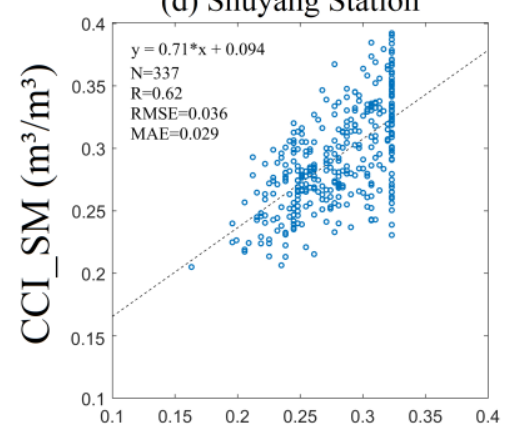

(g) No. 1 Huaiyin Station

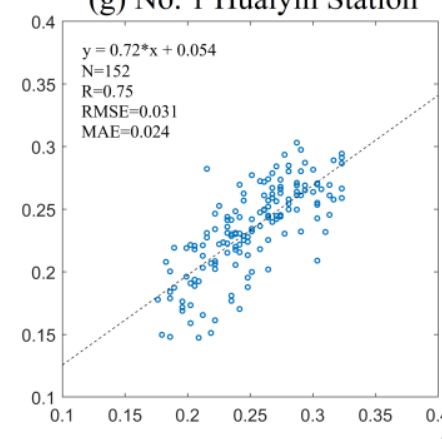

(b) Xuzhou Station

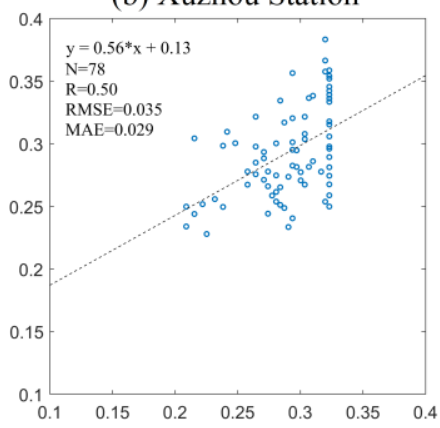

(e) Ganyu Station

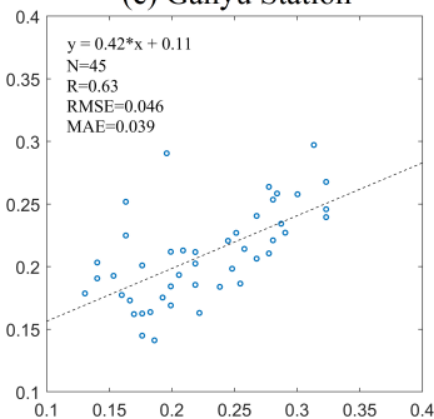

(h) No. 2 Huaiyin Station

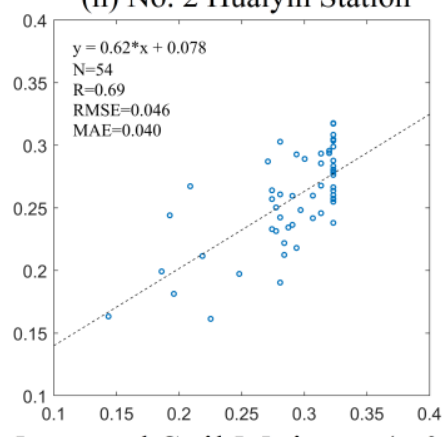

(c) Suining Station

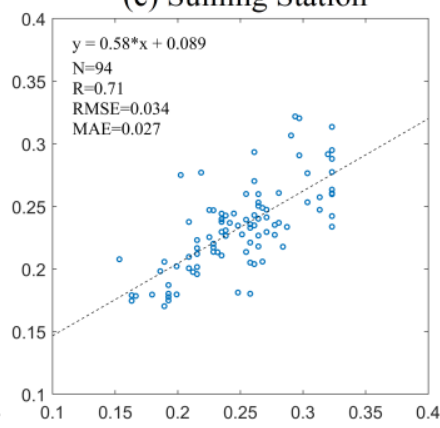

(f) Xuyi Station

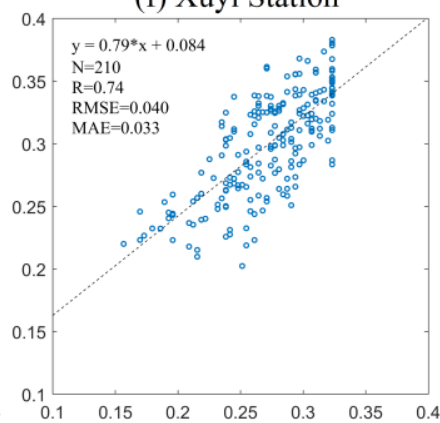

(i) Yangzhou Station

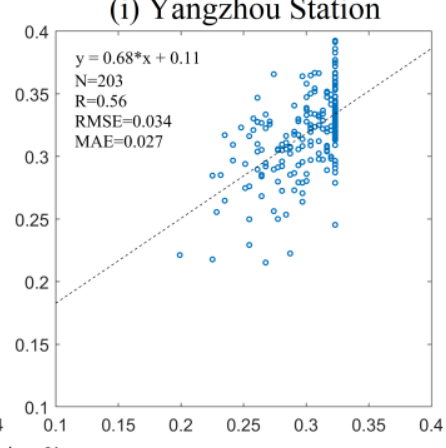

Measured Soil Moisture $\left(\mathrm{m}^{3} / \mathrm{m}^{3}\right)$

Figure 2 Scatter plots of measured soil moisture at each station and the ESA CCI_SM data in the study area during 1991-2013

Figure 4 shows the average soil moisture measured by stations in various regions of the study area from 1991 to 2013 along with the average CCI_SM and the evaluation indices. In Table 2, the average soil moisture per station in the study area, the average CCI_SM, and the evaluation index statistics from 1991 to 2013 are summarized. Xuzhou had the highest correlation between the CCI_SM and measured soil moisture data (R of 0.72 ) and the lowest RMSE and MAE among all regions (both 0.03). The second highest correlation was observed in Huai' an. In Yangzhou, the correlation with the measurement data was the lowest $(R=0.56)$. In addition, the difference between the average soil moisture measured in this region and the average ESA CCI_SM was also the greatest. In summary, the ESA CCI_SM data has relatively high quality in Xuzhou in the north of the South-toNorth Water Transfer Jiangsu Water Supply Zone, followed by Huai'an, Lianyungang, and Suqian in the central region. However, the data quality is relatively low in Yangzhou in the south. Dorigo et al., [75, 76] found good agreement between the ESA CCI_SM data and ground observation data in grasslands, agricultural areas, and semi-arid areas in temperate climate zones. However, it is difficult to capture the spatiotemporal characteristics of soil moisture when the area is particularly arid and humid. A possible cause of this could be the low signal-to-noise ratio of the satellite data collected in these 
regions or inadequate monitoring technology of some in situ detectors under extreme conditions [103].

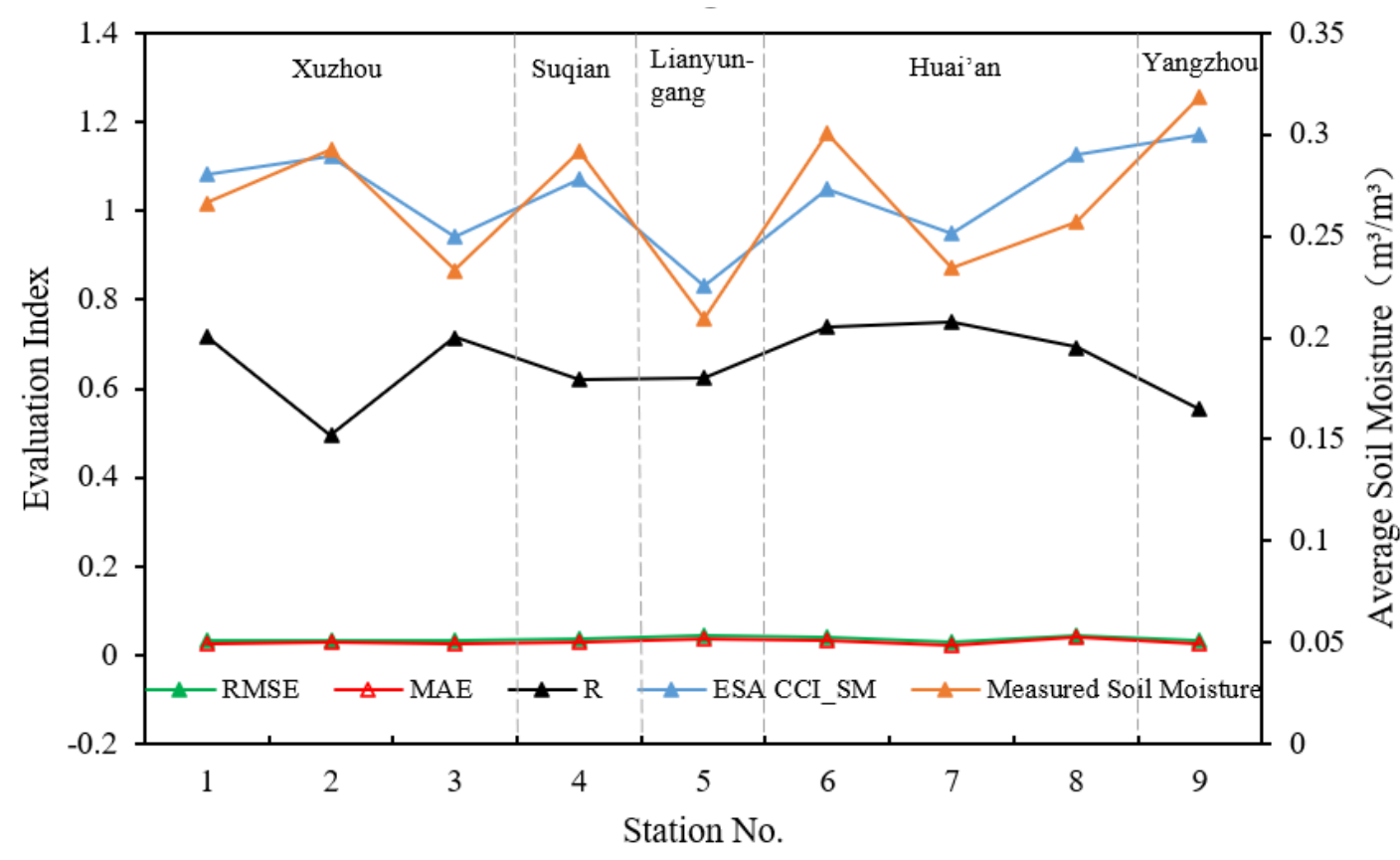

Figure 3 The average soil moisture per station, the average CCI_SM, and the evaluation indices in various regions of the study area from 1991-2013.

Table 2 The average soil moisture, average CCI_SM, and the evaluation indices per station in various regions of the study area from 1991-2013.

\begin{tabular}{cccccc}
\hline Region & ESA CCI_SM $\left(\mathrm{m}^{3} / \mathrm{m}^{3}\right)$ & Measured soil moisture $\left(\mathrm{m}^{3} / \mathrm{m}^{3}\right)$ & RMSE & MAE & $\mathrm{R}$ \\
\hline Xuzhou & 0.276 & 0.264 & 0.03 & 0.03 & 0.72 \\
Suqian & 0.278 & 0.292 & 0.04 & 0.03 & 0.62 \\
Lianyungang & 0.226 & 0.209 & 0.05 & 0.04 & 0.63 \\
Huai'an & 0.267 & 0.271 & 0.04 & 0.03 & 0.67 \\
Yangzhou & 0.300 & 0.319 & 0.03 & 0.03 & 0.56 \\
\hline
\end{tabular}

\subsection{Temporal variation of the CCI_SM data}

\subsubsection{Interannual variation}

The temporal variation of long-term microwave remote sensing soil moisture data were further analyzed after quality inspection and evaluation of the ESA CCI_SM data. Figure 5 shows the annual variation in the average and maximum soil moisture in the South-to-North Water Transfer Jiangsu Water Supply Zone between 1991 and 2019. The annual average CCI_SM fluctuated from $0.26-0.32 \mathrm{~m}^{3} / \mathrm{m}^{3}$ in the South-to-North Water Transfer Jiangsu Water Supply Zone, exhibiting an increasing trend overall. The minimum soil moisture was recorded in 1995 , which was $0.27 \mathrm{~m}^{3} / \mathrm{m}^{3}$. The maximum soil moistrure $\left(0.31 \mathrm{~m}^{3} / \mathrm{m}^{3}\right)$ was recorded in 2005 . A large fluctuation was observed during 1991-2005 and the maximum and average CCI_SM values showed strong fluctuations during 2004-2005. The fluctuation was small from 2006 to 2019 and exhibited a gradual increase. The fluctuation of the maximum CCI_SM showed a similar pattern as the average values. During 1991-1995, a decreasing trend was observed, followed by an increasing trend during 1996-2002, a strong fluctuation during 2003-2007, and finally a 
steady increase. The high soil moisture levels in 2005 may be related to abnormal precipitation during that year in the study area. Therefore, future analyses should consider the effects of meteorological conditions.

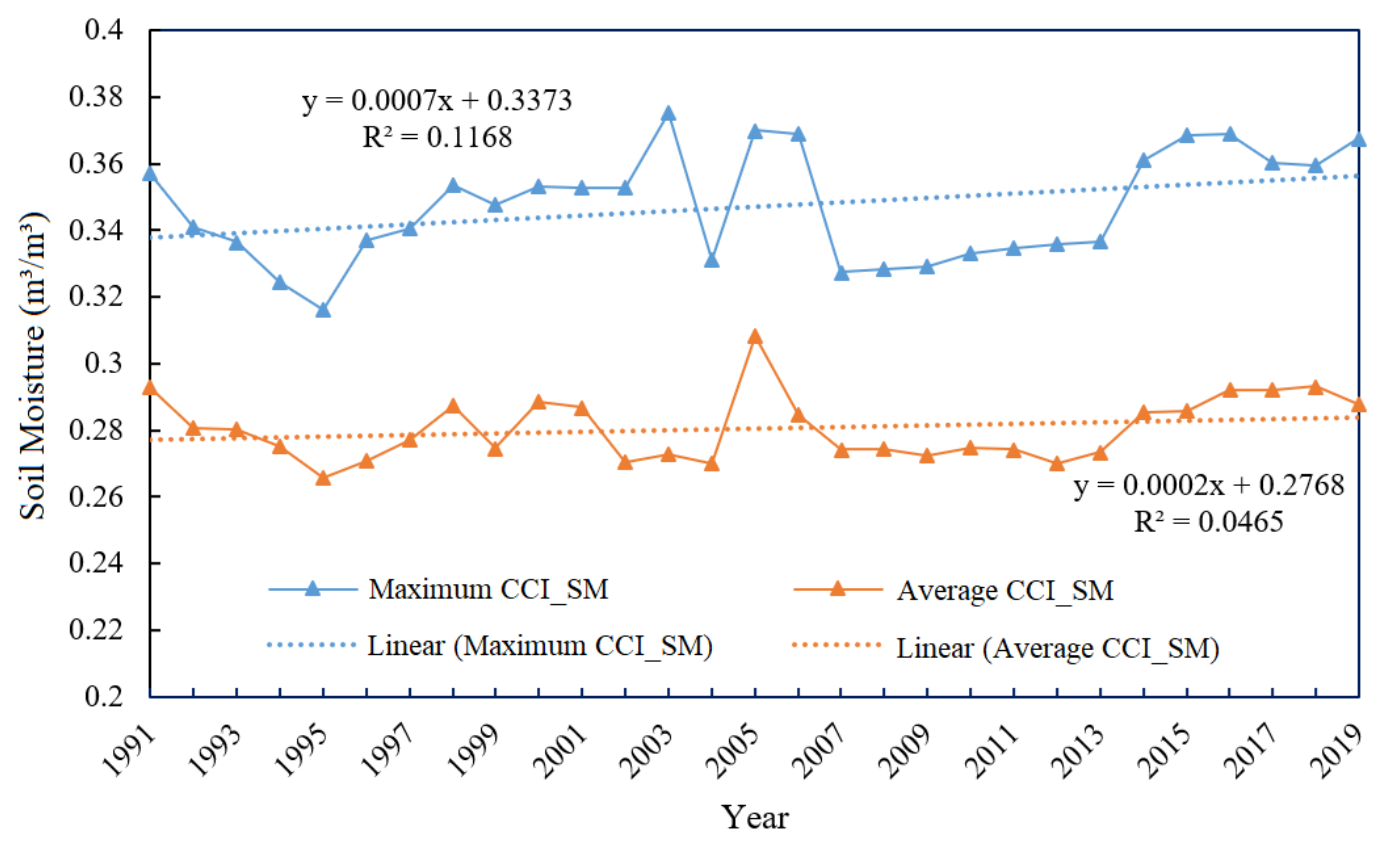

Figure 4 Annual variations in the average and maximum CCI_SM values in the study area from 1991-2019

\subsubsection{Monthly variation characteristics}

In Figure 6, the monthly variation in average soil moisture is presented for the Southto-North Water Transfer Jiangsu Water Supply Zone during 1991-2019. In the study area, soil moisture decreased rapidly from January to April, increased rapidly from May to July, reaching its annual maximum in July, and then began to fluctuate. Overall, the soil moisture showed an increasing trend throughout the year. This variation primarily resulted from the climatic characteristics of Jiangsu Province, which is characterized by a subtropical monsoon climate, with cold, dry winters and hot, humid summers. July and August showed the most precipitation and a relatively high level of soil moisture. In the spring, there was a drought, which was reflected as relatively low soil moisture. During autumn and winter, precipitation was reduced, but evaporation was also lower due to the lower temperatures, which resulted in relatively high soil moisture. Thus, the ESA CCI_SM data can describe the seasonal variation in soil moisture in the South-to-North Water Transfer Jiangsu Water Supply Zone. 


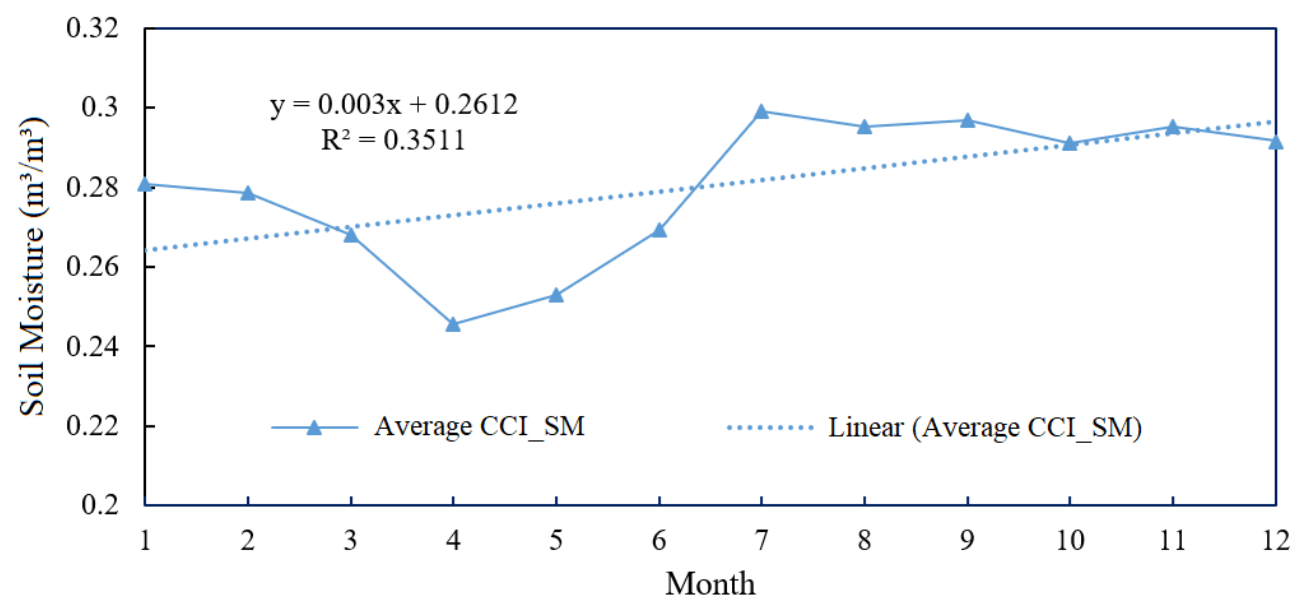

Figure 5 Monthly variation of the average CCI_SM in the study area during 19912019

\subsubsection{Periodic characteristics of soil moisture at typical pumping stations}

As a result of the indirect effects of hydrology, meteorology, and human activities on the soil ecological environment, the long-term soil moisture may exhibit periodic fluctuations. To evaluate these periodic fluctuation characteristics, 100 sets of Gaussian white noise (with a standard deviation of 0.2 ) were added to the soil moisture time series data from three typical pumping stations (the Gaogang, Hongze, and Liushan Stations in Figure 1) during the past 29 years in the South-to-North Water Transfer Jiangsu Water Supply Zone to perform EEMD. The EEMD decomposition results from the Gaogang, Hongze, and Liushan Stations are presented in Figures 7, 8, and 9, respectively. The three typical pumping stations returned 11 IMF components and one RSE component. Based on the decomposition results for three pumping stations, the IMF components appear to fluctuate around the zero line, with the local maximum and minimum being symmetrical. As the period of the decomposition component increased, the frequency gradually became smaller, and each IMF component represented the fluctuation in soil moisture over a specific period. The high-frequency component consisted primarily of Gaussian noise introduced by the EEMD method and short-term fluctuations in soil moisture, whereas the low-frequency component corresponded to long-term fluctuations in soil moisture [104]. The residual trend component represented the intrinsic development of the soil moisture time series.
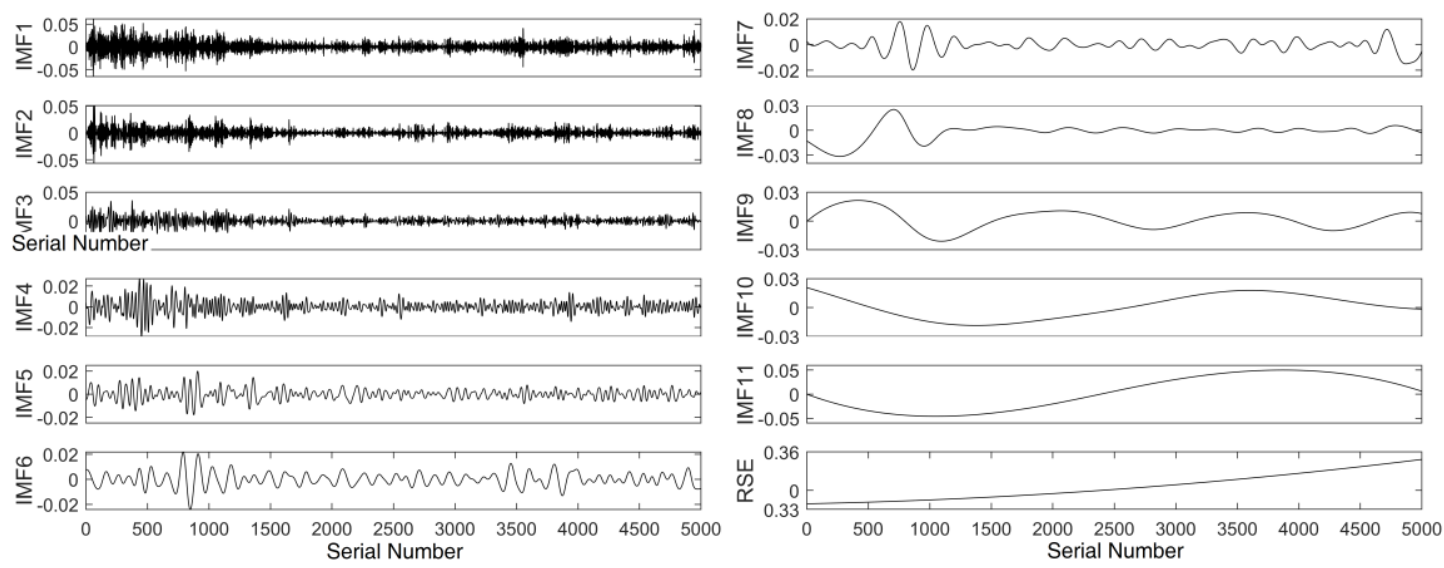

Figure 6 EEMD decomposition results of soil moisture for the Gaogang station 

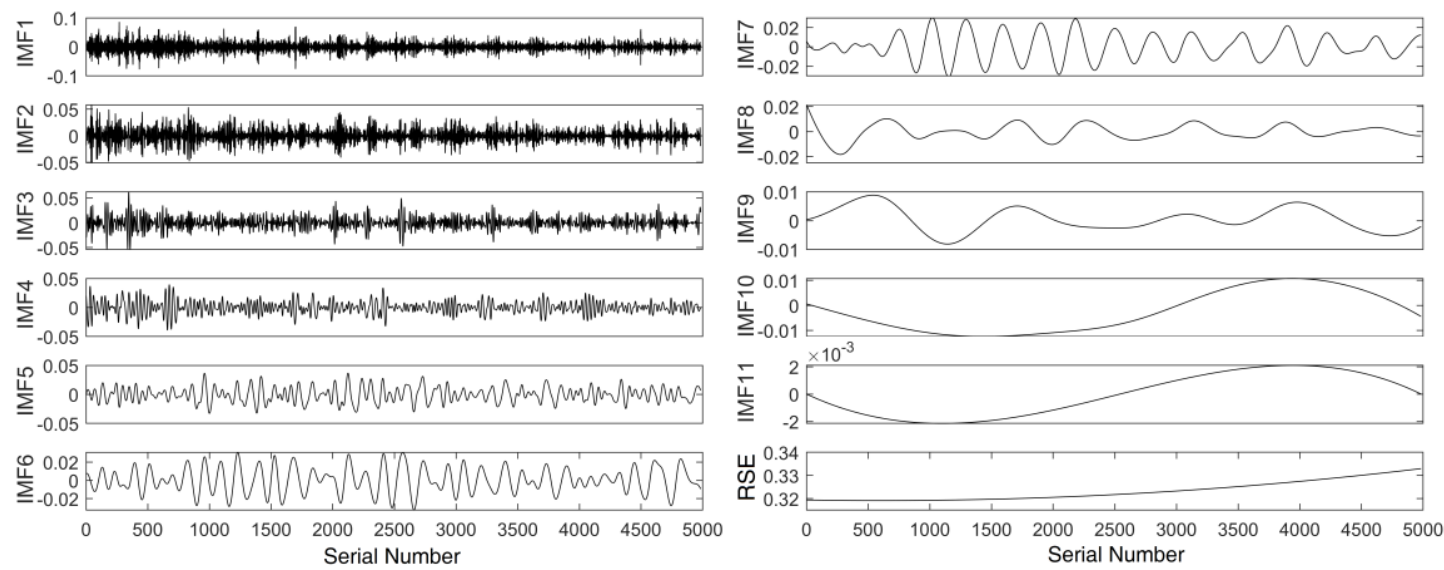

Figure 7 EEMD decomposition results of soil moisture for the Hongze station
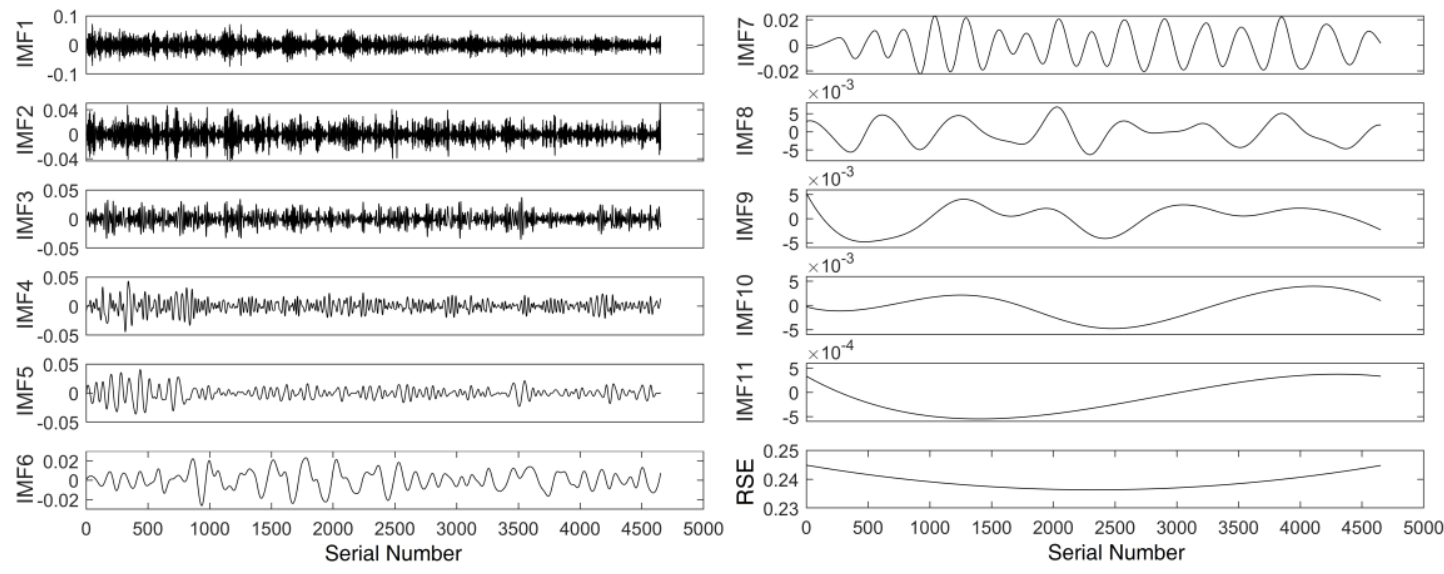

Figure 8 EEMD decomposition results of soil moisture for the Liushan station

A significance test was performed to determine whether the various IMF components derived from the EEMD decomposition of the soil moisture time series in the study area were true signal components or were Gaussian white noise (Figure 10). The closer the IMF was to the right of the horizontal axis, the longer the period was. The vertical axis represents the energy spectral density, and the closer a value is to the top, the higher the energy. The IMF components of soil moisture for the Gaogang and Hongze Stations passed the 1\% significance test, indicating that the ESA CCI_SM data for the Gaogang and Hongze Stations have multiple fluctuation periods, including seasonal to inter-annual and inter-decadal periods. Except for the IMF11 component, all the other components of soil moisture for the Liushan station passed the $5 \%$ significance test, indicating that the soil moisture for this station does not fluctuate significantly on a long time scale.
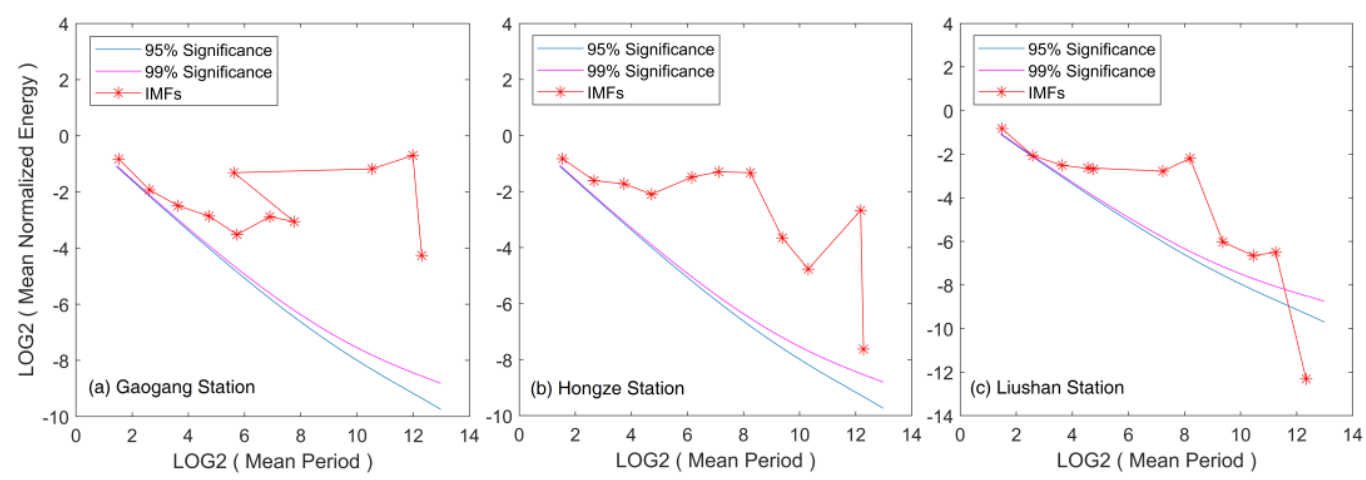
Figure 9 Significance tests for the pumping stations: (a) Gaogang Station; (b) Hongze Station; (c) Liushan Station

To evaluate the relative importance of each IMF component to the soil moisture time course data, the variance contribution rate was used to measure the degree of influence of each IMF component on the original data (Table 3). The results show that over the past 29 years, the 3.1-d period scale represented by the IMF1 component for the Gaoshan Station had the largest contribution (19.8\%), the 3.2-d period scale represented by the IMF1 component for the Hongze Station had the largest contribution $(19.4 \%)$, and the 3.0-d period scale represented by the IMF1 component for the Liushan Station had the largest contribution (33.1\%). The three pumping stations showed similar dominant periods of soil moisture, all of which were approximately $3.1 \mathrm{~d}$. This result indicates that the interdiurnal periodic fluctuations of soil moisture in the South-to-North Water Transfer Jiangsu Water Supply Zone are relatively strong. However, seasonal, interannual, and interdecadal periods cannot be neglected. For the soil moisture at the Gaoshan Station, the 3379.3-d period represented by the IMF10 component reached a variance contribution of $17.9 \%$, suggesting the presence of interdecadal soil moisture fluctuations at this station. For the soil moisture at the Hongze Station, the periods represented by IMF5, IMF6, and IMF7 components also had a variance contribution rate over $10 \%$, suggesting that the soil moisture at this station exhibits certain seasonal and interannual fluctuation characteristics. For the soil moisture at the Liushan Station, the 300.1-d period represented by the IMF10 component reached a variance contribution of $12.3 \%$, suggesting the presence of interannual soil moisture fluctuations at this station.

Table 3 The period and variance contribution of each IMF component of the soil moisture time series for typical pumping stations during 1991-2019

\begin{tabular}{|c|c|c|c|c|c|c|}
\hline \multirow{3}{*}{ IMF } & \multicolumn{6}{|c|}{ Pumping station } \\
\hline & \multicolumn{2}{|c|}{ Gaogang Station } & \multicolumn{2}{|c|}{ Hongze Station } & \multicolumn{2}{|c|}{ Liushan Station } \\
\hline & $\begin{array}{l}\text { Period } \\
\text { (d) }\end{array}$ & $\begin{array}{c}\text { Contribution rate } \\
(\%)\end{array}$ & $\begin{array}{l}\text { Period } \\
\text { (d) }\end{array}$ & $\begin{array}{c}\text { Contribution rate } \\
(\%)\end{array}$ & $\begin{array}{l}\text { Period } \\
\text { (d) }\end{array}$ & $\begin{array}{c}\text { Contribution rate } \\
(\%)\end{array}$ \\
\hline IMF1 & $3.1^{* *}$ & 19.8 & $3.2^{* *}$ & 19.4 & $3.0^{* *}$ & 33.1 \\
\hline IMF2 & $6.8^{* *}$ & 8.2 & $7.2^{* *}$ & 11.1 & $6.6^{*}$ & 14.1 \\
\hline IMF3 & $14.3^{* *}$ & 5.6 & $14.8^{* *}$ & 10.4 & $13.8^{* *}$ & 10.4 \\
\hline IMF4 & $27.1^{* *}$ & 4.2 & $30.6^{* *}$ & 8.0 & $30.7^{* *}$ & 8.9 \\
\hline IMF5 & $57.9^{* *}$ & 2.8 & $76.7^{* *}$ & 12.1 & $60.0^{* *}$ & 9.5 \\
\hline IMF6 & $120.7^{* *}$ & 4.3 & $148.7^{* *}$ & 13.5 & $163.2^{* *}$ & 9.2 \\
\hline IMF7 & $241.4^{* *}$ & 3.4 & $311.4^{* *}$ & 14.7 & $300.1^{* *}$ & 12.3 \\
\hline IMF8 & $506.9^{* *}$ & 12.3 & $664.4^{* *}$ & 3.2 & $664.6^{* *}$ & 1.0 \\
\hline IMF9 & $1689.7^{* *}$ & 13.1 & $1245.8^{* *}$ & 1.1 & $1860.8^{* *}$ & 0.6 \\
\hline $\begin{array}{c}\text { IMF1 } \\
0\end{array}$ & $3379.3^{* *}$ & 17.6 & $3322.0^{* *}$ & 5.1 & $3101.3^{* *}$ & 0.6 \\
\hline $\begin{array}{c}\text { IMF1 } \\
1\end{array}$ & $5069.0^{* *}$ & 1.7 & $4983.0^{* *}$ & 0.2 & 4652.0 & 0.0 \\
\hline RSE & - & 6.7 & - & 1.2 & - & 0.4 \\
\hline
\end{tabular}

* represents $\mathrm{P}<0.05$, ** represents $\mathrm{P}<0.01$ 
To determine the presence of abrupt changes in the soil moisture time series in the South-to-North Water Transfer Jiangsu Water Supply Zone and the corresponding occurrence time, the MK abrupt change test was employed to further analyze abrupt changes in soil moisture at three typical pumping stations (Figure 11).
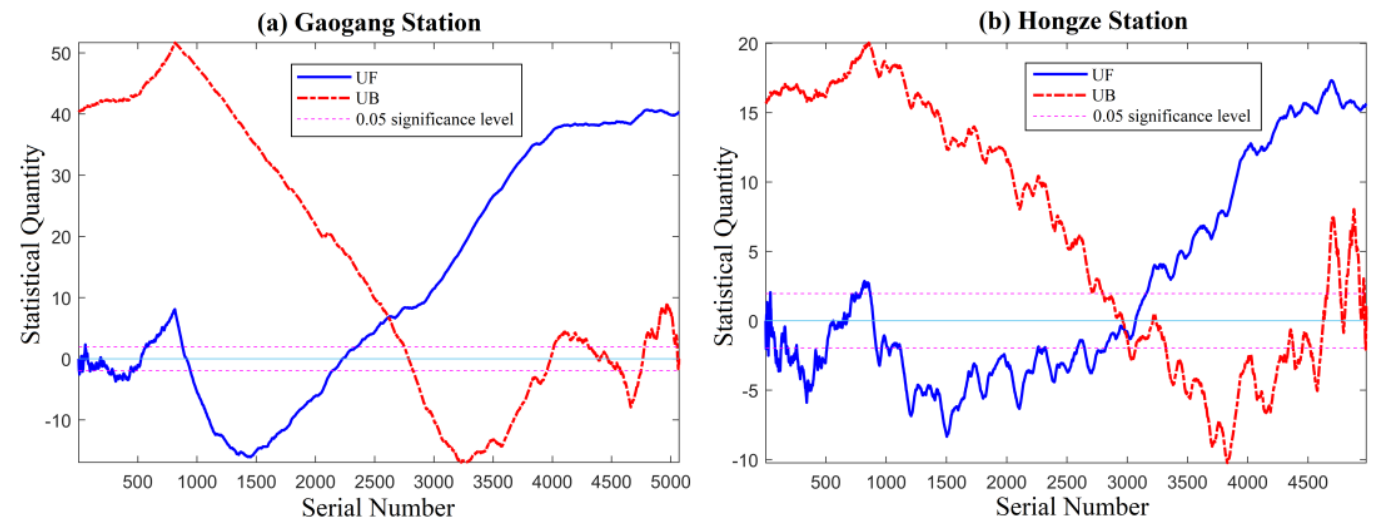

(c) Liushan Station

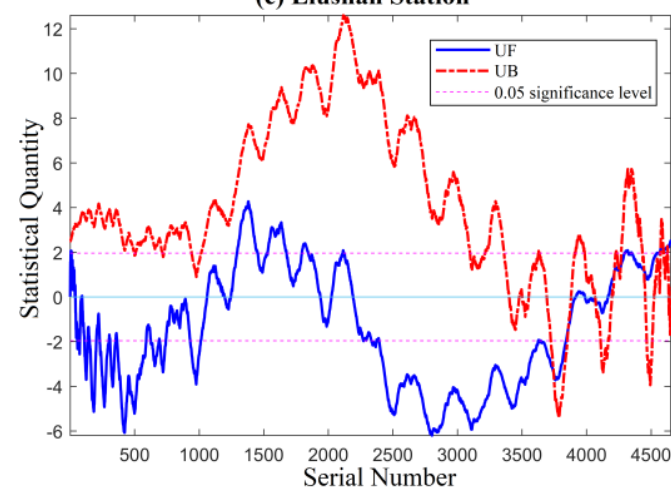

Figure 10 Abrupt changes of CCI_SM at three typical pumping stations: (a) Gaogang Station; (b) Hongze Station; and (c) Liushan Station

Based on the intersection of the UF and UB statistics for each station and the analysis of the variation in Figure 11, we determined the approximate occurrence time of abrupt changes in soil moisture for each station (Table 4). At the Gaogang Station, there was an intersection point between the UF and UB series curves that was outside of the 0.05 significance level, which suggests that there was no abrupt change at this station. At the Hongze Station, an abrupt change was observed in April 2014 that passed the 95\% significance test. Furthermore, the UF series curve showed a large fluctuation and there was a considerable difference between the UF and the UB curves after this point, indicating an abrupt increase in the soil moisture. At the Liushan Station, multiple intersections were observed between 2017 and 2019. Based on the variation observed at this station around 2018, it was estimated that the station experienced abrupt soil moisture changes in September 2017, April 2018, November 2018, and June 2019.

Table 4 Time of abrupt soil moisture changes at typical pumping stations

\begin{tabular}{ccccc} 
Pumping Station & $\begin{array}{c}\text { Time of the first } \\
\text { abrupt change }\end{array}$ & $\begin{array}{c}\text { Time of the second } \\
\text { abrupt change }\end{array}$ & $\begin{array}{c}\text { Time of the third } \\
\text { abrupt change }\end{array}$ & $\begin{array}{c}\text { Time of the fourth } \\
\text { abrupt change }\end{array}$ \\
\hline Gaogang Station & - & - & - & - \\
Hongze Station & April 2014 & - & November 2018 & June 2019 \\
Liushan Station & September 2017 & April 2018 & Jur
\end{tabular}


The Eastern Route of the South-to-North Water Diversion Project (ER-SNWDP) is a large-scale comprehensive water conservancy project involving the inter-basin allocation of water resources. This project is closely related to land remediation, ecological management, and the development of various resources in the North China Plain. Water was officially supplied in November 2013 following the completion of the first phase of the ER-SNWDP project in December 2002. As of 2020, the Eastern Route project has drawn over 33 billion $\mathrm{m}^{3}$ of water from the Yangtze River and 4.61 billion $\mathrm{m}^{3}$ of water has been transferred into Shandong Province. Since this inter-basin project involves multilevel water pumping and long-distance water delivery, there may be changes in the soil ecological environment along the coast or in local areas following water delivery. Thus, the abrupt changes in soil moisture at the Gaogang, Hongze, and Liushan stations mentioned above could be closely related to inter-basin water transfer.

\subsubsection{Soil moisture variation trends at typical pumping stations}

From the EEMD RSE and linear variation analysis of soil moisture at the pumping stations in the study area (Figure 11), overall increasing trends of soil moisture were observed over the past 29 years at the Gaogang, Hongze, and Liushan stations. The trend observed at the Liushan station exhibited two "decreasing-increasing"stages, shown as a change from an upward to a downward trend rather than a conventional linear trend. The moisture content of shallow soils is strongly influenced by precipitation and temperature [40]. During global warming, changes in precipitation and temperature are therefore important factors contributing to the observed transition in soil moisture at the Liushan Station.

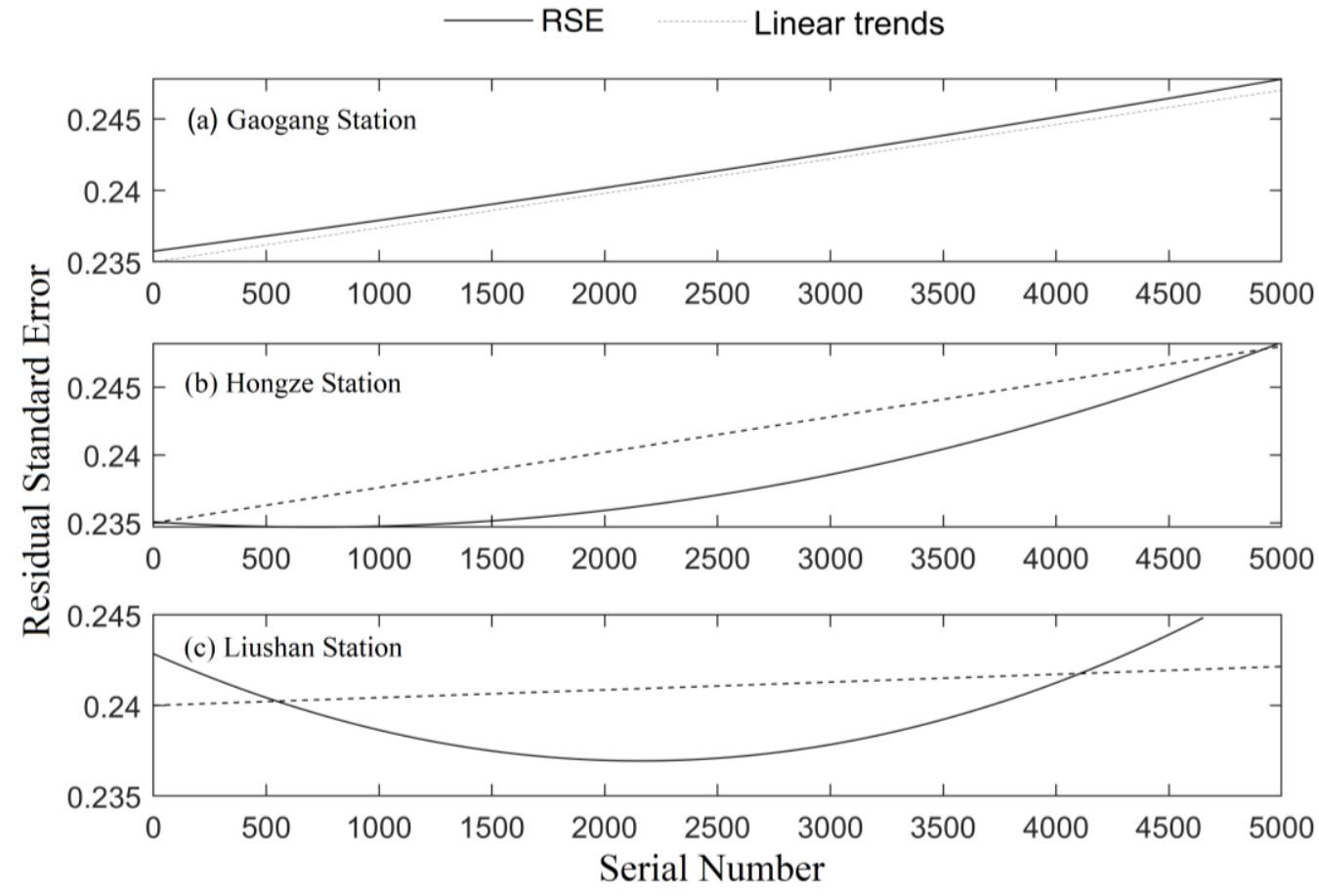

Figure 11 The soil moisture RSE and linear trend at typical pumping stations during 1991-2019: (a) Gaogang Station; (b) Hongze Station; and (c) Liushan Station

As shown in the MK analysis (Figure 12), the soil moisture UF curve for the Gaogang Station fluctuated around the zero line from January 1991 to February 1995. The UF curve did not exceed the significance level, indicating that the increasing and decreasing trends 
during this period were not significant. From March 1995 to December 1997, a downward trend was observed, and the decrease was particularly significant from March 1995 to November 1996. A segmented variation trend of "increasing-decreasing-increasing" was observed between December 1996 and December 2019. Specifically, the increase was significant from July 1998 to April 2007, the decrease was significant from August 2007 to September 2011, and the increase was significant from May 2012 to December 2019.

The soil moisture at the Hongze Station exhibited a "decreasing-increasing" trend from January 1991 to May 1992. There was a downward trend between June 1992 and June 2000, with a significant decrease from January 1994 to December 1997. An upward trend was observed between July 2000 and April 2007. From May 2007 to June 2014, a downward trend was evident, and the decrease was particularly significant from January 2008 to September 2013. Between July 2014 and December 2019, an upward trend was observed, with a significant increase from October 2014 to 2019.

At the Liushan Station, there were substantial fluctuations in the soil moisture UF curve. From January 1991 to May 1992, the UF curve showed an upward trend, although it was not statistically significant. From June 1991 to September 2007, the curve showed a downward trend. From October 2007 to May 2012, there was segmented "increasingdecreasing-increasing-decreasing-increasing" variation. Among the segments, significant increases were observed from August 2008 to May 2009, August 2009 to April 2010, and September 2010 to November 2010. From June 2012 to August 2018, we observed a downward trend, and the decrease was significant from February 2013 to August 2017. From September 2018 to December 2019, we observed an upward trend.

\subsection{Spatial variation of CCI_SM}

\subsubsection{Spatial distribution characteristics}

The spatial distribution of the annual average of CCI_SM in the study area during 1991-2019 is shown in Figure 13. In the South-to-North Water Transfer Jiangsu Water Supply Zone, the spatial distribution pattern of soil moisture is quite distinct. The ESA CCI_SM data provided a relatively adequate description of the spatial distribution of soil moisture in the study area, which is "north dry and south wet." The Xuzhou region in the northwest of the Jiangsu Water Supply Zone has a relatively low soil moisture (0.21-0.30 $\left.\mathrm{m}^{3} / \mathrm{m}^{3}\right)$ and the Lianyungang region in the northeast has a similar soil moisture $(0.23-0.32$ $\mathrm{m}^{3} / \mathrm{m}^{3}$ ). With decreasing latitude, soil moisture gradually increases. The soil moisture levels in the central Huai'an and Suqian regions are similar (approximately $0.24-0.33$ $\left.\mathrm{m}^{3} / \mathrm{m}^{3}\right)$. In the southern Yangzhou region, the soil moisture $\left(0.31-0.33 \mathrm{~m}^{3} / \mathrm{m}^{3}\right)$ is significantly higher than in other regions. The region with the highest soil moisture in the study area can be attributed to a dense river network and irrigated agriculture. 


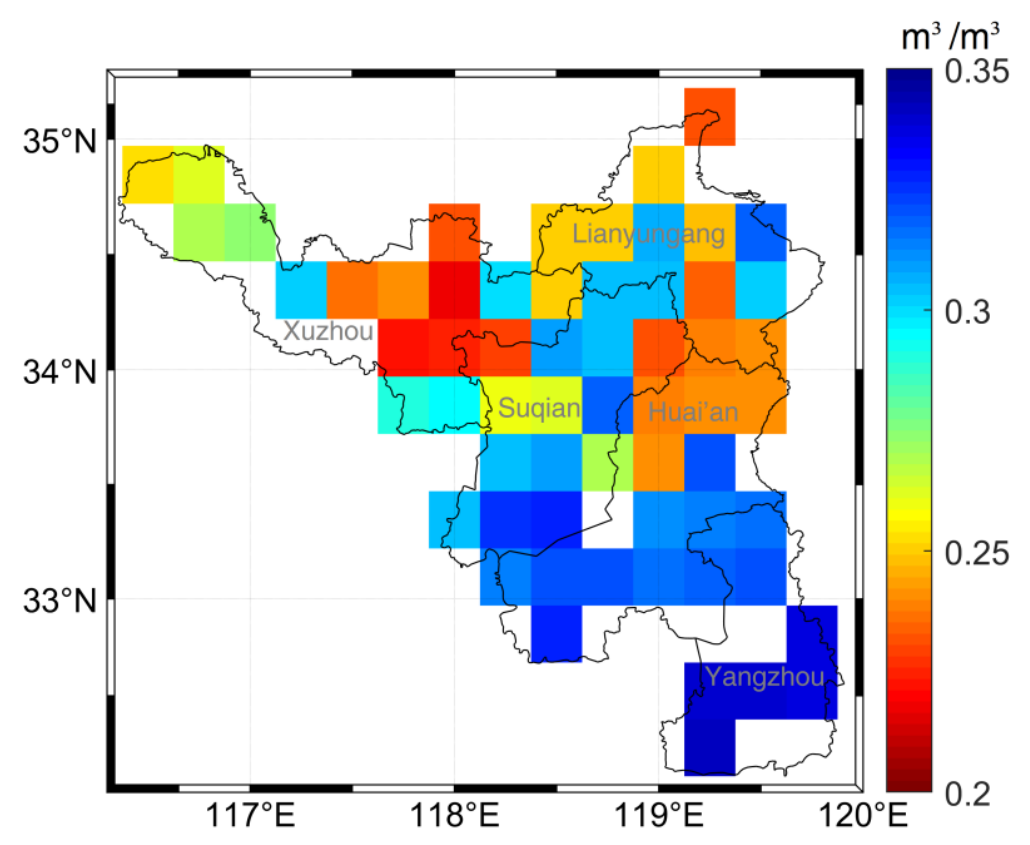

Figure 12 Spatial distribution of the annual CCI_SM in the study area from 19912019 (unit: $\mathrm{m}^{3} / \mathrm{m}^{3}$ )

The spatial CCI_SM distribution in the study area in different seasons from 19912019 are shown in Figure 14. The soil moisture levels were low in the spring due to low precipitation, continuous temperature increases, and greater evaporation than precipitation. In the northern region, the CCI_SM values were $0.2-0.3 \mathrm{~m}^{3} / \mathrm{m}^{3}$. In the southern region, they were $0.24-0.33 \mathrm{~m}^{3} / \mathrm{m}^{3}$. As a result of the monsoon climate in summer, precipitation increased, the flow of lakes and rivers within the water supply zone increased, and the soil moisture as quickly replenished by rainwater. Therefore, soil moisture was increased in comparison with spring. The soil moisture in the south is $0.25-$ $0.34 \mathrm{~m}^{3} / \mathrm{m}^{3}$. Even though the precipitation is less in autumn than in summer, the temperature is also significantly lower, resulting in reduced evaporation. In most parts of the study area, soil moisture increased compared to summer. Peak soil moisture was recorded in the south of Suqian, which exceeded $0.35 \mathrm{~m}^{3} / \mathrm{m}^{3}$. In winter, the soil moisture in the northern region was similar to that in autumn, while the soil moisture in the southern region increased. This may be caused by low temperatures and evaporation in winter. Overall, the South-to-North Water Transfer Jiangsu Water Supply Zone experiences the wettest soil during the winter and the driest soil during the spring. The soil moisture in most of the study area gradually increases from spring to winter. This seasonal variation in soil moisture is consistent with the general knowledge of the climate and water cycle pattern in the study area. 

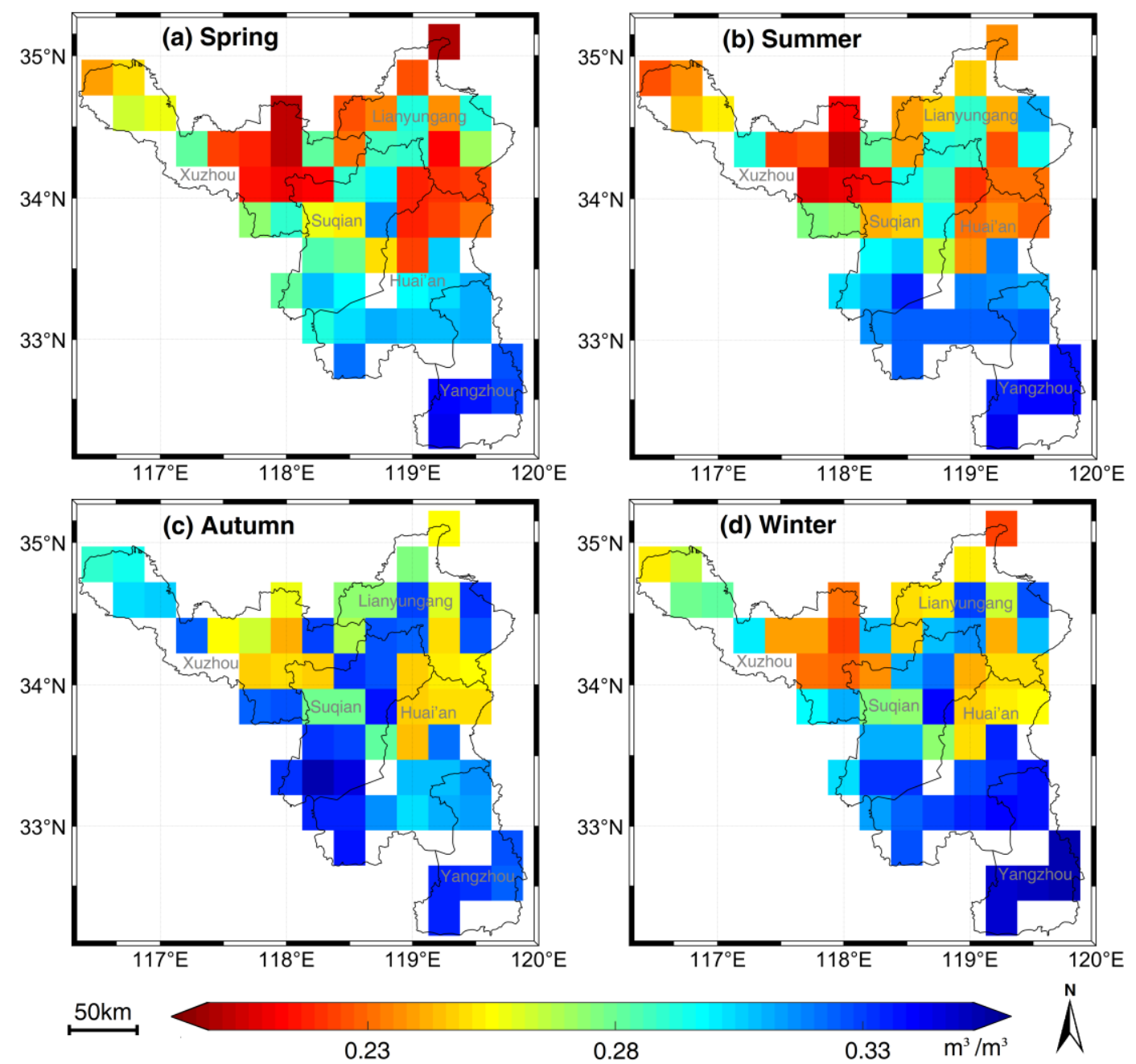

Figure 13 The spatial CCI_SM distribution in the study area in different seasons during 1991-2019 (unit: $\mathrm{m}^{3} / \mathrm{m}^{3}$ ). (a) spring, (b) summer, (c) autumn, and (d) winter.

\subsubsection{Spatial variation characteristics}

Figure 15 shows the CCI_SM variation and significance test results in the study area from 1991 to 2019. The CCI_SM in the Jiangsu Water Supply Zone showed an overall increasing trend over the past 29 years. There was increasing soil moisture in $86.9 \%$ of the study area, and $67.9 \%$ of the areas exceeded the $5 \%$ significance level. There was decreasing soil moisture in $13.1 \%$ of the study area, only $13.5 \%$ of which exceeded the $5 \%$ significance level.

From a spatial perspective, the soil moisture in Pizhou in the northern part of Xuzhou decreased significantly $(\mathrm{P}<0.05)$, and the decrease exceeded 0.02 . The soil moisture in the southern part of Suqian decreased slightly, but the downward trend was not statistically significant $(\mathrm{P}>0.05)$. This phenomenon is due to the relatively low soil moisture level in Suqian. In the central and eastern regions of the study area, the soil moisture increased. In Guanyun County in the south of Lianyungang, soil moisture did not increase substantially, but the increasing trend was significant $(\mathrm{P}<0.01)$. In most areas of Huai'an, significantly increased soil moisture was observed, with the increase in the central Hongze and Huai'an Districts exceeding 0.04. Moreover, the increased soil moisture in the central and western regions of Yangzhou exceeded 0.06 , which was significant $(\mathrm{P}<0.01)$. 


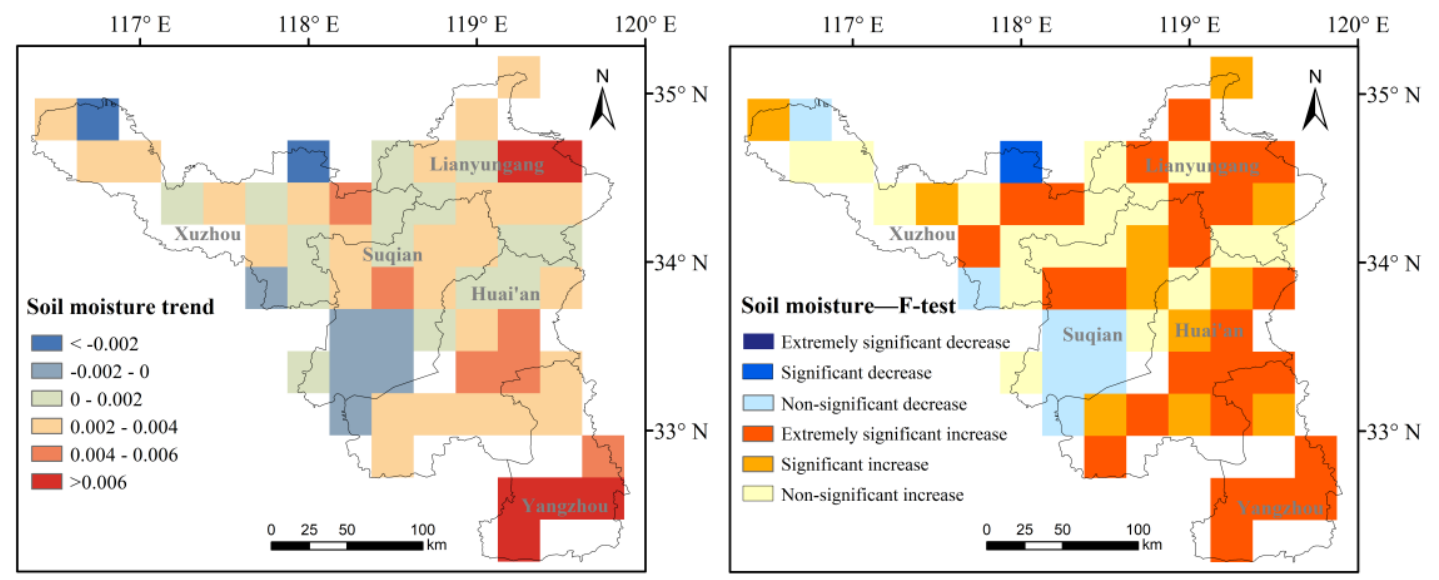

Figure 14 CCI_SM variation in the study area during 1991-2019 and significance test results

\section{Discussion}

\subsection{The effect of underlying surface on soil moisture pattern}

The huge heterogeneity of the spatial and temporal distribution of soil moisture and the lack of standard methods for estimating this characteristic limit its quantification and application in research [105]. The underlying surface with high spatial heterogeneity has an important influence on the spatial change of soil moisture. The underlying surface types in the JWSA of the South-to-North Water Transfer Project include arable land, forest, grassland, water area, urban and rural residential areas, etc. Arable land is divided into different agricultural landscapes such as paddy fields and dry fields. Different agricultural landscapes have obvious effects on the scale, pattern and spatial distribution characteristics of surface soil moisture. Arable land shows that soil moisture is highly correlated with soil texture and soil rock content, and is also related to differences in land management. Soil moisture varies greatly in places with low soil porosity. Arable land agricultural landscepes exhibits huge spatial variability in soil moisture at the watershed scale. The spatial pattern of soil moisture depends on the heterogeneity of soil property, precipitation and land use. Evapotranspiration causes small scale spatial pattern changes in soil moisture during the crop growing season.

JWSA has an area of 68.7 million acres of arable land, 0.86 acres of arable land per capita, and has a sea area of 37,500 square kilometers and a total of 26 islands. JWSA is rich in wetland resources, the area of wetland is 2,821,900 hectares, including 1,953,200 hectares of natural wetland and 868,700 hectares of artificial wetland. The distribution of wetlands is mainly coastal and coastal wetlands, southern JWSA is dominated by lakes, rivers, and marshes, Lixiahe area is dominated by rivers and lakes, and northern JWSA is dominated by artificial water conveyance rivers and canals. JWSA has a forest area of 1.56 million hectares, a forest coverage rate of $22.8 \%$, a total standing tree stock volume of 96.09 million cubic meters, 76 state-owned forest farms covering an area of 106,700 hectares. Jiangsu straddles the North China Platform and the Yangtze Platform, two major geological structural units. Non-ferrous metals, building materials, gypsum salts, and special non-metallic minerals are the characteristics and advantages of Jiangsu's mineral resources.

During the drought, the net effect of vegetation on soil moisture was significantly greater in grassland than in forests, indicating that the temporal heterogeneity of soil moisture content is related to resource uptake. The soil under grass and shrubs is the wettest at the beginning of the growing season, but the driest at the end [106]. Both linear correlation analysis and empirical orthogonal function analysis indicate that the soil 
texture of moist forest hillsides is the dominant factor affecting soil moisture distribution [107]. The distribution of soil moisture on hillsides is related to soil properties, topography, soil depth and spatial distribution of vegetation. Soil moisture distribution is the key link between hydrological and ecological processes in semi-arid grasslands and shrubs, as it affects evapotranspiration, respiration and assimilation [108]. In this region, grassland dynamics are closely related to available water, but it has proven difficult to address the aspects of climate-driven vegetation change. Part of the reason is that it is currently unclear how soil heterogeneity affects the response of plants to climate [109]. The spatial variation of groundwater level will cause additional spatial variation of soil moisture and surface water flux. This additional variability may be important for storm development in areas with high groundwater levels in most areas [110]. In areas where vegetation dynamics vary greatly from year to year, we observe the negative impact of vegetation correction on soil moisture, and the correlation decreases. It emphasizes the need for dynamic vegetation correction in areas with large inter-annual variability [111]. Linking soil moisture and runoff in urban areas can improve rainfall runoff simulation. In the urban areas, impervious surface are always negatively correlated with soil moisture, while most natural surfaces are positively correlated with soil moisture in rural areas [112]. The underlying surface spatial pattern determines the spatial distribution pattern of soil moisture in the JWSA, which is basically consistent with the spatial distribution pattern of the results of this study.

\subsection{The effect of meteorological factors on soil moisture pattern}

Soil moisture is positively correlated with daily average precipitation, and negatively correlated with sunshine, air temperature and ground temperature. Changes in spatial soil moisture patterns are more sensitive to changes in ground temperature than changes in air temperature. Therefore, the spatial variability of soil moisture is greatly affected by meteorological factors, and each meteorological factor has a certain duration for the spatial variability of soil moisture on a regional scale [113]. The terrain of JWSA is dominated by plains. The land area of JWSA is 103,229.17 square kilometers, of which, the plain area accounts for $86.89 \%$, reaching $89,706.03$ square kilometers, the hilly area is 11916.16 square kilometers, and the mountain area is 1,06.98 square kilometers. JWSA is located in the mid-latitude zone on the east coast of the Asian continent and belongs to the East Asian monsoon climate zone. It is in the transitional zone between subtropical and warm temperate climate. Generally, it is bounded by the Huaihe River and the main irrigation canal in northern JWSA. The area to the north has a warm temperate humid and semi-humid monsoon climate; the area to the south has a subtropical humid monsoon climate. JWSA has a coastline of more than 1,000 kilometers, and the ocean has a significant impact on the climate of Jiangsu. Under the combined influence of solar radiation, atmospheric circulation, and JWSA's specific geographic location and geomorphic features, JWSA's basic climate characteristics are: mild climate, four distinct seasons, significant monsoons, cold winters and hot summers, variable temperatures in spring, high air in autumn, and rain and heat in the same season. Abundant rainfall, concentrated precipitation, significant rainy season, abundant light and heat.

The annual average temperature of JWSA is between $13.6-16.1^{\circ} \mathrm{C}$, and the distribution is decreasing from south to north. The highest value of annual average temperature appears in Dongshan in the south, and the lowest value appears in Ganyu in the north. The annual precipitation in JWSA is 704-1250 $\mathrm{mm}$. The precipitation from the central part of JWSA to the north of Hongze Lake is less than $1000 \mathrm{~mm}$, and the precipitation in the south is more than $1000 \mathrm{~mm}$. The rainfall distribution is more in the south than in the north, and more on the coast than inland. The annual runoff depth of rainfall in JWSA is between 150 and $400 \mathrm{~mm}$. The Jiangsu Plain is widely distributed with deep Quaternary loose deposits and abundant groundwater sources. Meteorological factors such as precipitation, temperature, and sunshine have an important influence on the temporal change of soil moisture. These meteorological factors have different temporal change 
cycles. The coupling effect of several meteorological factors causes the temporal variation period of soil moisture in JWSA to be maintained at about 3 days. Around, there are also significant seasonal variation characteristics and inter-annual variation cycles.

\subsection{The effect of water conservancy facilities on soil moisture pattern}

The East Route of the South-to-North Water Diversion Project is planned to divert water from the main stream of the Yangtze River near Yangzhou, Jiangsu Province, and use the Beijing-Hangzhou Grand Canal and parallel rivers to transport water to connect Hongze Lake, Luoma Lake, Nansi Lake, and Dongping Lake, and serve as a storage reservoir. After pumping water into Dongping Lake step by step, the pumping station divides water into two ways. After crossing the Yellow River all the way north, it flows to Tianjin by itself. The main water supply line from the Yangtze River to Tianjin Beidagang Reservoir is about 1,156 kilometers long. Under the action of resource allocation projects (mainly pumping station projects and river projects) in the JWSA, hydrological characteristics and water resources allocation patterns have changed significantly, and land cover patterns and landscape patterns have changed accordingly. As one of the control elements of the ecological environment, hydrology is a key factor leading to land cover changes. The type, coverage, pattern and changes of land cover affect the hydrological process of the ecological environment. Both are the key elements of the ecological environment. Acting on the ecological, economic and social complex system, affecting the evolution of the structure and function of this system. The construction of water conservancy projects is the behavior of human beings to significantly alter the surface hydrological pattern with engineering measures. The study of changes in hydrological conditions and land cover changes caused by water conservancy projects has received attention, but it is far from forming a study on the interaction mechanism between hydrology and land cover changes. The east route of the South-to-North Water Diversion Project was opened in December 2013. After the completion of the South-toNorth Water Diversion Project, especially some large pumping stations or water delivery channels, the water level rises, the water surface widens, the water flow slows down, the radiation balance increases, the heat capacity of the water body increases, and the natural state of the underlying surface has undergone major changes. Have different degrees of impact on local temperature, precipitation, humidity, wind, fog, and evaporation. As a result, the average annual temperature in the reservoir area has risen slightly. In spring and summer, the temperature in the reservoir area is lower than that in the surrounding areas. In autumn and winter, the water surface temperature is higher than that on land. The precipitation in the central area and adjacent areas of the reservoir area has decreased, especially the precipitation in the central area may be reduced by $10 \%$, and the precipitation in the peripheral areas of the reservoir, especially in areas with downwind or higher terrain, has increased. After the construction of the reservoir, the annual average temperature has risen slightly, while the underlying surface has sufficient water sources, enhanced evaporation, and increased air humidity. Compared with the surrounding area of the reservoir, the relative humidity can increase by $3 \%-5 \%$ on average. After the water transfer started in December 2013, the soil moisture field measurement sites of the JWSA, Hongze Station and Liushan Station, had sudden changes in the field measurement of soil moisture in April 2014 and September 2017, indicating that the water conservancy facilities of the South-to-North Water Diversion Project have the temporal and spatial changes of local soil moisture have a certain influence.

\subsection{The effect of remote sensing product resolution on soil moisture pattern}

The spatial resolution of soil moisture products is crucial for their applications in different fields. Coarse-resolution soil moisture products are not suitable for regional hydrology and water resources management, agricultural irrigation and production applications, but such coarse-resolution soil moisture products are suitable for characterizing the spatial and temporal distribution pattern of soil moisture. For the 
description of the spatial distribution pattern of soil moisture in a small area or a small spatial scale, remote sensing products with finer resolution are needed. The data used in this study is ESA CCI remote sensing soil moisture, which is based on active and passive microwave sensors, and produces long-term series containing active data sets, passive data sets and fusion data sets (1979-2019), a multi-satellite fusion of soil moisture satellite data products. The spatial resolution is $0.25^{\circ}$, and the temporal resolution is 1 day. Because of the relatively coarse spatial resolution and fine time resolution of ESA CCI products, the use of ESA CCI products to study the spatial and temporal distribution pattern of soil moisture in JWSA is very satisfactory. In particular, the fine time resolution of ESA CCI can accurately identify the impact of the South-to-North Water Diversion Project on the changes in the temporal and spatial patterns of the JWSA after the start of water supply. These global soil moisture products, which are usually extracted from microwave remote sensing data, have a spatial resolution on the order of tens of kilometers. Regional hydrological and agricultural applications require a spatial resolution of several kilometers or even tens of meters. Resolution is generally not suitable for regional hydrological and agricultural applications, such as irrigation management and flood forecasting. In this context, scholars have proposed various downscaling methods to improve the spatial resolution of soil moisture. Satellite remote sensing technology has been widely used to estimate the surface soil moisture. Efforts have been made to develop many global soil moisture products. However, these global soil moisture products extracted from microwave remote sensing are generally not suitable for regional hydrological and agricultural applications, such as irrigation management and flood forecasting, due to their coarse spatial resolution. Therefore, various downscaling methods have been proposed to improve the coarse resolution of soil moisture products. With the help of upscaling of measured soil moisture at the point scale, the assessment of the spatial pattern of downscaling soil moisture will be strengthened.

Various methods are used for remote sensing of soil moisture downscaling. There are three main categories: methods based on satellite remote sensing data fusion, methods based on statistical models, and methods based on auxiliary geographic information. These methods have made great progress in the process of microwave remote sensing of soil moisture downscaling, but there are also many problems. Since soil moisture is affected by the interaction of factors such as soil properties, surface cover, topography, precipitation, temperature, etc., soil moisture has a strong spatial heterogeneity. Therefore, the main problem of the remote sensing soil moisture downscaling method is the uncertainty of the results, the uncertainty of the scale model, the scale limitation of the auxiliary information for downscaling, the uncertainty of the field measured soil moisture, and the verification of the downscaling results. The future research direction in this area may be to produce long-term, time-continuous, and high-spatial resolution soil moisture data sets through downscaling methods.

\section{Conclusions}

In this study, we used the measured soil moisture in the South-to-North Water Transfer Jiangsu Water Supply Zone during 1991-2-13 and the 1991-2019 CCI_SM data to verify the accuracy of the CCI_SM data. Then, EEMD, MK abrupt change test, and regression analyses were employed to explore the spatiotemporal variation in soil moisture in the South-to-North Water Transfer Jiangsu Water Supply Zone from 19912019. The following conclusions were obtained:

(1) The CCI data exhibited good correlations with the measured data at 9 stations, $(\mathrm{R}=0.69)$. The remote sensing data are comparable to the measured data (RMSE $=0.036$ and $\mathrm{MAE}=0.029$ ). The highest $\mathrm{CCI}$ data quality was observed for the Xuzhou region in the north of the South-to-North Water Transfer Jiangsu Water 
Supply Zone, followed by the central Huai' an, Lianyungang, and Suqian regions. The lowest data quality was found for the Yangzhou region in the south.

(2) The CCI_SM remote sensing data accurately reflects the annual and monthly variation in soil moisture in the South-to-North Water Transfer Jiangsu Water Supply Zone.

(3) The EEMD method was used to investigate the periodic characteristics of soil moisture at three typical pumping stations (Gaogang, Hongze, and Liushan Stations) in the study area from 1991-2019. The soil moisture data at these three stations were found to exhibit significant interdiurnal periodic fluctuations, and their typical periods were similar (all around $3.1 \mathrm{~d}$ ). Nevertheless, long time periods cannot be neglected. For example, the periods of $3379.3 \mathrm{~d}$ for Gaogang Station, $311.4 \mathrm{~d}$ for Honze Station, and $300.1 \mathrm{~d}$ for Liushan Station also exhibited significant fluctuations. According to the RSE trends, the soil moisture at the three stations all exhibited an overall increasing trend, while the trend observed for Liushan Station contained two stages of " decreasing-increasing."

(4) The MK method was used to test abrupt changes in soil moisture. The results show that during 1991-2019, no abrupt change occurred at Gaogang Station. In contrast, an abrupt changes was observed in April 2014 at Hongze Station, and abrupt changes occurred at four time points from 2017 to 2019 at Liushan Station.

(5) The CCI_SM remote sensing data accurately described the "north dry and south wet" spatial distribution pattern of soil moisture in the South-to-North Water Transfer Jiangsu Water Supply Zone. There are evident seasonal variations in soil moisture, which is highest in winter, lower in autumn, and even lower in spring and summer. This pattern conforms relatively well with the actual situation. Thus, the CCI_SM data is applicable to the analysis of soil moisture variations in the South-to-North Water Transfer Jiangsu Water Supply Zone.

(6) Over the past 29 years, the soil moisture in the South-to-North Water Transfer Jiangsu Water Supply Zone mainly exhibited an increasing trend. Regions with significantly increased soil moisture levels are mainly distributed in the Yangzhou and Huai'an regions in the southeast of the Jiangsu Water Supply Zone. The area with a significant decrease is relatively small, concentrated mainly in the northern part of Xuzhou.

Our results show that the CCI_SM data can compensate for the uneven distribution of measuring stations and missing data. In addition, this dataset can also provide longterm data for the analysis of temporal and spatial variation characteristics, serving as data support for large-scale agricultural drought and flood research in the South-to-North Water Transfer Jiangsu Water Supply Zone. However, a single observation station cannot represent a wide range of soil moisture values. Additionally, CCI data have low spatial resolution and can be impacted by land cover patterns. Therefore, there will be a relatively large error between measured soil moisture and the remote sensing data for the corresponding area. Thus, absolute verification of remote sensing data cannot fully reflect the actual situation of CCI data, so other relative verification methods should be adopted. Considering the lack of CCI data in certain regions, the relatively large deviation from measured values at some stations, and the low spatial resolution, we suggest that the influence of other factors - such as topography, precipitation, evaporation, temperature, vegetation cover, land cover pattern, etc. - should be used to study multi-source data fusion technologies and downscaling techniques. In this way, the application of CCI data 
for fine-scale applications such as agricultural and hydrological simulations is possible, thereby further enhancing the value of ESA CCI_SM data.

\begin{abstract}
Author Contributions: Conceptualization, J.C., Y.W. and Y.L.; methodology, Y.W.; software, Y.W., J.L. and Y.Z.; validation, X.F.; formal analysis, J.C., Y.W.; investigation, Y.L.; resources, J.C.; data curation, Y.W.; writing-original draft preparation, Y.W., J.C.; writing-review and editing, J.C.,; visualization, X.F.; supervision, J.C.; project administration, J.C.; funding acquisition, J.C.; critical feedback, W.W. All authors have read and agreed to the published version of the manuscript.
\end{abstract}

Funding: This research was funded by Natural Science Foundation of Jiangsu Province, grant number BK20201121 and National Natural Science Foundation of China, grant number 41930102、 41871313 .

Acknowledgments: We are grateful to the ESA CCI Soil Moisture Team from Vienna University of Technology (TUWien), members of DEM research group from Nanjing Normal University and the members of department of geographic information science in Nanjing Xiaozhuang University. We really appreciate the editors and anonymous reviewers for their meaningful comments for improving our manuscript.

Conflicts of Interest: The authors declare no conflict of interest.

\title{
References
}

1. Robock, A.; Vinnikov, K. Y.; Schlosser, C. A.; Speranskaya, N. A.; Xue, Y. Use of midlatitude soil moisture and meteorological observations to validate soil moisture simulations with biosphere and bucket models. Journal of Climate 1995, 8(1), 15-35.

2. Brocca, L.; Melone, F.; Moramarco, T.; Wagner, W.; Naeimi, V.; Bartalis, Z.; Hasenauer, S. Improving runoff prediction through the assimilation of the ASCAT soil moisture product. Hydrology and Earth System Sciences, 2010, 14(10), $1881-1893$.

3. Guo, Z.; Dirmeyer, P. A.; Hu, Z. Z.; Gao, X.; Zhao, M. Evaluation of the Second Global Soil Wetness Project soil moisture simulations: 2. Sensitivity to external meteorological forcing. Journal of Geophysical Research: Atmospheres, 2006, 111(D22).

4. Wagner, W.; Naeimi, V.; Scipal, K.; de Jeu, R.; Martínez-Fernández, J. Soil moisture from operational meteorological satellites. Hydrogeology Journal, 2007, 15(1), 121-131.

5. Prasad, R.; Deo, R. C.; Li, Y.; Maraseni, T. Ensemble committee-based data intelligent approach for generating soil moisture forecasts with multivariate hydro-meteorological predictors. Soil and Tillage Research, 2018, 181, 63-81.

6. Vogel, E.; Lerat, J.; Pipunic, R.; Frost, A. J.; Donnelly, C.; Griffiths, M.; Loh, S. Seasonal ensemble forecasts for soil moisture, evapotranspiration and runoff across Australia. Journal of Hydrology, 2021, 601, 126620.

7. Crow, W. T.; Chen, F.; Reichle, R. H.; Xia, Y.; Liu, Q. Exploiting soil moisture, precipitation, and streamflow observations to evaluate soil moisture/runoff coupling in land surface models. Geophysical research letters, 2018, 45(10), 4869-4878.

8. Zhu, P.; Zhang, G.; Wang, H.; Zhang, B.; Liu, Y. Soil moisture variations in response to precipitation properties and plant communities on steep gully slope on the Loess Plateau. Agricultural Water Management, 2021, 256, 107086.

9. Liu, Y.; Cui, Z.; Huang, Z.; López-Vicente, M.; Wu, G. L. Influence of soil moisture and plant roots on the soil infiltration capacity at different stages in arid grasslands of China. Catena, 2019, 182, 104147.

10. Small, E. E.; Badger, A. M.; Abolafia-Rosenzweig, R.; Livneh, B. Estimating soil evaporation using drying rates determined from satellite-based soil moisture records. Remote Sensing, 2018, 10(12), 1945.

11. Ghajarnia, N.; Kalantari, Z.; Orth, R.; Destouni, G. Close co-variation between soil moisture and runoff emerging from multicatchment data across Europe. Scientific reports, 2020, 10(1), 1-11.

12. Short Gianotti, D. J.; Akbar, R.; Feldman, A. F.; Salvucci, G. D.; Entekhabi, D. Terrestrial evaporation and moisture drainage in a warmer climate. Geophysical Research Letters, 2020, 47(5), e2019GL086498.

13. Lei, F.; Crow, W. T.; Holmes, T. R.; Hain, C.; Anderson, M. C. Global investigation of soil moisture and latent heat flux coupling strength. Water resources research, 2018, 54(10), 8196-8215.

14. Yao, Y.; Zhang, Y.; Liu, Q.; Liu, S.; Jia, K.; Zhang, X.; Fisher, J. B. Evaluation of a satellite-derived model parameterized by three soil moisture constraints to estimate terrestrial latent heat flux in the Heihe River basin of Northwest China. Science of the Total Environment, 2019, 695, 133787.

15. Seo, E.; Lee, M. I.; Jeong, J. H.; Koster, R. D.; Schubert, S. D.; Kim, H. M.; Scaife, A. A. Impact of soil moisture initialization on boreal summer subseasonal forecasts: mid-latitude surface air temperature and heat wave events. Climate Dynamics, 2019, 52(3), 1695-1709. 
16. Shrestha, P.; Kurtz, W.; Vogel, G.; Schulz, J. P.; Sulis, M.; Hendricks Franssen, H. J.; Simmer, C. Connection between root zone soil moisture and surface energy flux partitioning using modeling, observations, and data assimilation for a temperate grassland site in Germany. Journal of Geophysical Research: Biogeosciences, 2018, 123(9), 2839-2862.

17. Green, J. K.; Seneviratne, S. I.; Berg, A. M.; Findell, K. L.; Hagemann, S.; Lawrence, D. M.; Gentine, P. Large influence of soil moisture on long-term terrestrial carbon uptake. Nature, 2019, 565(7740), 476-479.

18. Qiu, B.; Xue, Y.; Fisher, J. B.; Guo, W.; Berry, J. A.; Zhang, Y. Satellite chlorophyll fluorescence and soil moisture observations lead to advances in the predictive understanding of global terrestrial coupled carbon-water cycles. Global Biogeochemical Cycles, 2018, 32(3), 360-375.

19. Ardilouze, C.; Batté, L.; Bunzel, F.; Decremer, D.; Déqué, M.; Doblas-Reyes, F. J.; Prodhomme, C. Multi-model assessment of the impact of soil moisture initialization on mid-latitude summer predictability. Climate Dynamics, 2017, 49(11), 3959-3974.

20. Lee, C. S.; Sohn, E.; Park, J. D.; Jang, J. D. Estimation of soil moisture using deep learning based on satellite data: A case study of South Korea. GIScience \& Remote Sensing, 2019, 56(1), 43-67.

21. Gruber, A.; Scanlon, T.; van der Schalie, R.; Wagner, W.; Dorigo, W. Evolution of the ESA CCI Soil Moisture climate data records and their underlying merging methodology. Earth System Science Data, 2019, 11(2), 717-739.

22. Klotzsche, A.; Jonard, F.; Looms, M. C.; van der Kruk, J.; Huisman, J. A. Measuring soil water content with ground penetrating radar: A decade of progress. Vadose Zone Journal, 2018, 17(1), 1-9.

23. Rawat, K. S.; Sehgal, V. K.; Ray, S. S.; Singh, S. K. A Time Domain Reflectometery (TDR) based estimation of soil moisture. Bulletin of Environmental and Scientific Research, 2019, 8(4), 7-10.

24. Kim, D. J.; Yu, J. D.; Byun, Y. H. Horizontally Elongated Time Domain Reflectometry System for Evaluation of Soil Moisture Distribution. Sensors, 2020, 20(23), 6834.

25. Surya, S. G.; Yuvaraja, S.; Varrla, E.; Baghini, M. S.; Palaparthy, V. S.; Salama, K. N. An in-field integrated capacitive sensor for rapid detection and quantification of soil moisture. Sensors and Actuators B: Chemical, 2020, 321, 128542.

26. Goswami, M. P.; Montazer, B.; Sarma, U. Design and characterization of a fringing field capacitive soil moisture sensor. IEEE Transactions on Instrumentation and Measurement, 2018, 68(3), 913-922.

27. Franz, T. E.; Zreda, M.; Ferre, T. P. A.; Rosolem, R. An assessment of the effect of horizontal soil moisture heterogeneity on the area-average measurement of cosmic-ray neutrons. Water Resources Research, 2013, 49(10), 6450-6458.

28. McJannet, D.; Franz, T.; Hawdon, A.; Boadle, D.; Baker, B.; Almeida, A.; Desilets, D. Field testing of the universal calibration function for determination of soil moisture with cosmic-ray neutrons. Water Resources Research, 2014, 50(6), 5235-5248.

29. Jakobi, J.; Huisman, J. A.; Schrön, M.; Fiedler, J.; Brogi, C.; Vereecken, H.; Bogena, H. R. Error estimation for soil moisture measurements with cosmic ray neutron sensing and implications for rover surveys. Frontiers in water, $2020,2,10$.

30. Calamita, G.; Brocca, L.; Perrone, A.; Piscitelli, S.; Lapenna, V.; Melone, F.; Moramarco, T. Electrical resistivity and TDR methods for soil moisture estimation in central Italy test-sites. Journal of Hydrology, 2012, 454, 101-112.

31. Nijland, W.; Van der Meijde, M.; Addink, E. A.; De Jong, S. M. Detection of soil moisture and vegetation water abstraction in a Mediterranean natural area using electrical resistivity tomography. Catena, 2010, 81(3), 209-216.

32. Dick, J.; Tetzlaff, D.; Bradford, J.; Soulsby, C. Using repeat electrical resistivity surveys to assess heterogeneity in soil moisture dynamics under contrasting vegetation types. Journal of hydrology, 2018, 559, 684-697.

33. SU, S. L.; Singh, D. N.; Baghini, M. S. A critical review of soil moisture measurement. Measurement, 2014, 54, 92-105.

34. Benítez-Buelga, J.; Rodríguez-Sinobas, L.; Sánchez Calvo, R.; Gil-Rodríguez, M.; Sayde, C.; Selker, J. S. Calibration of soil moisture sensing with subsurface heated fiber optics using numerical simulation. Water Resources Research, 2016, 52(4), 29852995.

35. Wang, M.; Li, X.; Chen, L.; Hou, S.; Wu, G.; Deng, Z. A modified soil water content measurement technique using actively heated fiber optic sensor. Journal of Rock Mechanics and Geotechnical Engineering, 2020, 12(3), 608-619.

36. Vidana Gamage, D. N.; Biswas, A.; Strachan, I. B.; Adamchuk, V. I. Soil water measurement using actively heated fiber optics at field scale. Sensors, 2018, 18(4), 1116.

37. Guillod, B. P.; Orlowsky, B.; Miralles, D. G.; Teuling, A. J.; Seneviratne, S. I. Reconciling spatial and temporal soil moisture effects on afternoon rainfall. Nature communications, 2015, 6(1), 1-6.

38. Zhao, L.; Yang, K.; Qin, J.; Chen, Y.; Tang, W.; Montzka, C.; Vereecken, H. Spatiotemporal analysis of soil moisture observations within a Tibetan mesoscale area and its implication to regional soil moisture measurements. Journal of Hydrology, 2013, 482, 92-104. 
39. Ma, H.; Zeng, J.; Chen, N.; Zhang, X.; Cosh, M. H.; Wang, W. Satellite surface soil moisture from SMAP, SMOS, AMSR2 and ESA CCI: A comprehensive assessment using global ground-based observations. Remote Sensing of Environment, 2019, 231, 111215.

40. Zhao, W.; Sánchez, N.; Lu, H.; Li, A. A spatial downscaling approach for the SMAP passive surface soil moisture product using random forest regression. Journal of hydrology, 2018, 563, 1009-1024.

41. Wang, J.; Ge, Y.; Heuvelink, G.; Zhou, C. Upscaling in situ soil moisture observations to pixel averages with spatio-temporal geostatistics. Remote Sensing, 2015, 7(9), 11372-11388.

42. Llamas, R. M.; Guevara, M.; Rorabaugh, D.; Taufer, M.; Vargas, R. Spatial gap-filling of ESA CCI satellite-derived soil moisture based on geostatistical techniques and multiple regression. Remote Sensing, 2020, 12(4), 665.

43. Paruta, A.; Ciraolo, G.; Capodici, F.; Manfreda, S.; Dal Sasso, S. F.; Zhuang, R.; Maltese, A. A Geostatistical Approach to Map Near-Surface Soil Moisture Through Hyperspatial Resolution Thermal Inertia. IEEE Transactions on Geoscience and Remote Sensing, 2020, 59(6), 5352-5369.

44. Landrum, C.; Castrignanó, A.; Zourarakis, D.; Mueller, T. Assessing the time stability of soil moisture patterns using statistical and geostatistical approaches. Agricultural Water Management, 2016, 177, 118-127.

45. Chen, M.; Willgoose, G. R.; Saco, P. M. Spatial prediction of temporal soil moisture dynamics using HYDRUS-1D. Hydrological processes, 2014, 28(2), 171-185.

46. Coopersmith, E. J.; Cosh, M. H.; Petersen, W. A.; Prueger, J.; Niemeier, J. J. Soil moisture model calibration and validation: An ARS watershed on the South Fork Iowa River. Journal of Hydrometeorology, 2015, 16(3), 1087-1101.

47. Afshar, F. A.; Ayoubi, S.; Jafari, A. The extrapolation of soil great groups using multinomial logistic regression at regional scale in arid regions of Iran. Geoderma, 2018, 315, 36-48.

48. Paloscia, S.; Pettinato, S.; Santi, E.; Notarnicola, C.; Pasolli, L.; Reppucci, A. J. R. S. O. E. Soil moisture mapping using Sentinel1 images: Algorithm and preliminary validation. Remote Sensing of Environment, 2013, 134, 234-248.

49. Zreda, M.; Shuttleworth, W. J.; Zeng, X.; Zweck, C.; Desilets, D.; Franz, T.; Rosolem, R. COSMOS: The cosmic-ray soil moisture observing system. Hydrology and Earth System Sciences, 2012, 16(11), 4079-4099.

50. Evans, J. G.; Ward, H. C.; Blake, J. R.; Hewitt, E. J.; Morrison, R.; Fry, M.; Jenkins, A. Soil water content in southern England derived from a cosmic-ray soil moisture observing system-COSMOS-UK. Hydrological Processes, 2016, 30(26), 4987-4999.

51. Montzka, C.; Bogena, H. R.; Zreda, M.; Monerris, A.; Morrison, R.; Muddu, S.; Vereecken, H. Validation of spaceborne and modelled surface soil moisture products with cosmic-ray neutron probes. Remote sensing, 2017, 9(2), 103.

52. Mujumdar, M.; Goswami, M. M.; Morrison, R.; Evans, J. G.; Ganeshi, N.; Sabade, S. S.; Patil, S. N. A study of field-scale soil moisture variability using the COsmic-ray Soil Moisture Observing System (COSMOS) at IITM Pune site. Journal of Hydrology, 2021, 597, 126102.

53. Chew, C.; Small, E. E.; Larson, K. M. An algorithm for soil moisture estimation using GPS-interferometric reflectometry for bare and vegetated soil. GPS solutions, 2016, 20(3), 525-537.

54. Camps, A.; Park, H.; Pablos, M.; Foti, G.; Gommenginger, C. P.; Liu, P. W.; Judge, J. Sensitivity of GNSS-R spaceborne observations to soil moisture and vegetation. IEEE Journal of Selected Topics in Applied Earth Observations and Remote Sensing, 2016, 9(10), 4730-4742.

55. Chew, C. C.; Small, E. E. Soil moisture sensing using spaceborne GNSS reflections: Comparison of CYGNSS reflectivity to SMAP soil moisture. Geophysical Research Letters, 2018, 45(9), 4049-4057.

56. Reichle, R. H.; Koster, R. D.; Liu, P.; Mahanama, S. P.; Njoku, E. G.; Owe, M. Comparison and assimilation of global soil moisture retrievals from the Advanced Microwave Scanning Radiometer for the Earth Observing System (AMSR-E) and the Scanning Multichannel Microwave Radiometer (SMMR). Journal of Geophysical Research: Atmospheres, 2007, 112(D9).

57. Kawanishi, T.; Sezai, T.; Ito, Y.; Imaoka, K.; Takeshima, T.; Ishido, Y.; Spencer, R. W. The Advanced Microwave Scanning Radiometer for the Earth Observing System (AMSR-E), NASDA's contribution to the EOS for global energy and water cycle studies. IEEE Transactions on Geoscience and Remote Sensing, 2003, 41(2), 184-194.

58. Tachi, K.; Arai, K.; Sato, Y. Advanced microwave scanning radiometer (AMSR): Requirements and preliminary design study. IEEE transactions on geoscience and remote sensing, 1989, 27(2), 177-183.

59. Koike, T.; Nakamura, Y.; Kaihotsu, I.; Davaa, G.; Matsuura, N.; Tamagawa, K.; Fujii, H. Development of an advanced microwave scanning radiometer (AMSR-E) algorithm for soil moisture and vegetation water content. Proceedings of Hydraulic Engineering, 2004, 48, 217-222.

60. Cho, E.; Moon, H.; Choi, M. First assessment of the Advanced Microwave Scanning Radiometer 2 (AMSR2) soil moisture contents in Northeast Asia. Journal of the Meteorological Society of Japan. Ser. II, 2015, 93(1), 117-129. 
61. Kim, S.; Liu, Y. Y.; Johnson, F. M.; Parinussa, R. M.; Sharma, A. A global comparison of alternate AMSR2 soil moisture products: Why do they differ?. Remote Sensing of Environment, 2015, 161, 43-62.

62. Entekhabi, D.; Njoku, E. G.; O'Neill, P. E.; Kellogg, K. H.; Crow, W. T.; Edelstein, W. N.; Van Zyl, J. The soil moisture active passive (SMAP) mission. Proceedings of the IEEE, 2010, 98(5), 704-716.

63. Chan, S. K.; Bindlish, R.; O'Neill, P. E.; Njoku, E.; Jackson, T.; Colliander, A.; Kerr, Y. Assessment of the SMAP passive soil moisture product. IEEE Transactions on Geoscience and Remote Sensing, 2016, 54(8), 4994-5007.

64. Colliander, A.; Jackson, T. J.; Bindlish, R.; Chan, S.; Das, N.; Kim, S. B.; Yueh, S. Validation of SMAP surface soil moisture products with core validation sites. Remote Sensing of Environment, 2017, 191, 215-231.

65. Kerr, Y. H.; Waldteufel, P.; Richaume, P.; Wigneron, J. P.; Ferrazzoli, P.; Mahmoodi, A.; Delwart, S. The SMOS soil moisture retrieval algorithm. IEEE transactions on geoscience and remote sensing, 2012, 50(5), 1384-1403.

66. Kerr, Y. H.; Waldteufel, P.; Wigneron, J. P.; Martinuzzi, J. A. M. J.; Font, J.; Berger, M. Soil moisture retrieval from space: The Soil Moisture and Ocean Salinity (SMOS) mission. IEEE transactions on Geoscience and remote sensing, 2001, 39(8), $1729-1735$.

67. Kerr, Y. H.; Al-Yaari, A.; Rodriguez-Fernandez, N.; Parrens, M.; Molero, B.; Leroux, D.; Wigneron, J. P. Overview of SMOS performance in terms of global soil moisture monitoring after six years in operation. Remote Sensing of Environment, 2016, 180, 40-63.

68. Cui, Y.; Long, D.; Hong, Y.; Zeng, C.; Zhou, J.; Han, Z.; Wan, W. Validation and reconstruction of FY-3B/MWRI soil moisture using an artificial neural network based on reconstructed MODIS optical products over the Tibetan Plateau. Journal of Hydrology, 2016, 543, 242-254.

69. Song, C.; Jia, L. A method for downscaling FengYun-3B soil moisture based on apparent thermal inertia. Remote Sensing, 2016, 8(9), 703.

70. Paloscia, S.; Pettinato, S.; Santi, E.; Notarnicola, C.; Pasolli, L.; Reppucci, A. J. R. S. O. E. Soil moisture mapping using Sentinel1 images: Algorithm and preliminary validation. Remote Sensing of Environment, 2013, 134, 234-248.

71. Bauer-Marschallinger, B.; Freeman, V.; Cao, S.; Paulik, C.; Schaufler, S.; Stachl, T.; Wagner, W. Toward global soil moisture monitoring with Sentinel-1: Harnessing assets and overcoming obstacles. IEEE Transactions on Geoscience and Remote Sensing, 2018, 57(1), 520-539.

72. Hornacek, M.; Wagner, W.; Sabel, D.; Truong, H. L.; Snoeij, P.; Hahmann, T.; Doubková, M. Potential for high resolution systematic global surface soil moisture retrieval via change detection using Sentinel-1. IEEE Journal of Selected Topics in Applied Earth Observations and Remote Sensing, 2012, 5(4), 1303-1311.

73. Balenzano, A.; Mattia, F.; Satalino, G.; Lovergine, F. P.; Palmisano, D.; Peng, J.; Jackson, T. J. Sentinel-1 soil moisture at 1 km resolution: a validation study. Remote Sensing of Environment, 2021, 263, 112554.

74. Amazirh, A.; Merlin, O.; Er-Raki, S.; Gao, Q.; Rivalland, V.; Malbeteau, Y.; Escorihuela, M. J. Retrieving surface soil moisture at high spatio-temporal resolution from a synergy between Sentinel-1 radar and Landsat thermal data: A study case over bare soil. Remote sensing of environment, 2018, 211, 321-337.

75. Dorigo, W. A.; Gruber, A.; De Jeu, R. A. M.; Wagner, W.; Stacke, T.; Loew, A.; Kidd, R. Evaluation of the ESA CCI soil moisture product using ground-based observations. Remote Sensing of Environment, 2015, 162, 380-395.

76. Dorigo, W.; Wagner, W.; Albergel, C.; Albrecht, F.; Balsamo, G.; Brocca, L.; Lecomte, P. ESA CCI Soil Moisture for improved Earth system understanding: State-of-the art and future directions. Remote Sensing of Environment, 2017, 203, $185-215$.

77. McNally, A.; Shukla, S.; Arsenault, K. R.; Wang, S.; Peters-Lidard, C. D.; Verdin, J. P. Evaluating ESA CCI soil moisture in East Africa. International Journal of Applied Earth Observation and Geoinformation, 2016, 48, 96-109.

78. An, R.; Zhang, L.; Wang, Z.; Quaye-Ballard, J. A.; You, J.; Shen, X.; Ke, Z. Validation of the ESA CCI soil moisture product in China. International journal of applied earth observation and geoinformation, 2016, 48, 28-36.

79. Gruber, A.; Scanlon, T.; van der Schalie, R.; Wagner, W.; Dorigo, W. Evolution of the ESA CCI Soil Moisture climate data records and their underlying merging methodology. Earth System Science Data, 2019, 11(2), 717-739.

80. Zhang, L.; Liu, Y.; Ren, L.; Jiang, S.; Yang, X.; Yuan, F.; Wei, L. Drought monitoring and evaluation by ESA CCI soil moisture products over the Yellow River Basin. IEEE Journal of Selected Topics in Applied Earth Observations and Remote Sensing, 2019, 12(9), 3376-3386.

81. Zhang, G.; Su, X.; Ayantobo, O. O.; Feng, K. Drought monitoring and evaluation using ESA CCI and GLDAS-Noah soil moisture datasets across China. Theoretical and Applied Climatology, 2021, 144(3), 1407-1418.

82. Zhou, K.; Li, J.; Zhang, T.; Kang, A. The use of combined soil moisture data to characterize agricultural drought conditions and the relationship among different drought types in China. Agricultural Water Management, 2021, 243, 106479. 
83. Ford, T. W.; Quiring, S. M. Comparison of contemporary in situ, model, and satellite remote sensing soil moisture with a focus on drought monitoring. Water Resources Research, 2019, 55(2), 1565-1582.

84. Yuan, X.; Ma, Z.; Pan, M.; Shi, C. Microwave remote sensing of short-term droughts during crop growing seasons. Geophysical Research Letters, 2015, 42(11), 4394-4401.

85. Ma, S.; Zhang, S.; Wu, Q.; Wang, J. Long-term changes in surface soil moisture based on CCI SM in Yunnan Province, Southwestern China. Journal of Hydrology, 2020, 588, 125083.

86. Long, D.; Yang, W.; Scanlon, B. R.; Zhao, J.; Liu, D.; Burek, P.; Wada, Y. South-to-North Water Diversion stabilizing Beijing's groundwater levels. Nature communications, 2020, 11(1), 1-10.

87. Zhang, J.; Zhang, Y.; Sun, G.; Song, C.; Dannenberg, M. P.; Li, J.; Hao, L. Vegetation greening weakened the capacity of water supply to China's South-to-North Water Diversion Project. Hydrology and Earth System Sciences, 2021, 25(10), 5623-5640.

88. Zhang, C.; Duan, Q.; Yeh, P. J. F.; Pan, Y.; Gong, H.; Moradkhani, H.; Guo, X. Sub-regional groundwater storage recovery in North China Plain after the South-to-North water diversion project. Journal of Hydrology, 2021, 597, 126156.

89. Liu, J.; Li, M.; Wu, M.; Luan, X.; Wang, W.; Yu, Z. Influences of the south-to-north water diversion project and virtual water flows on regional water resources considering both water quantity and quality. Journal of Cleaner Production, 2020, 244, 118920

90. Wang, X.; He, X.; Xiao, R.; Song, M.; Jia, D. Millimeter to centimeter scale precision water-level monitoring using GNSS reflectometry: Application to the South-to-North Water Diversion Project, China. Remote Sensing of Environment, 2021, 265, 112645.

91. Wei, Y.; Tang, D.; Ding, Y.; Agoramoorthy, G. Incorporating water consumption into crop water footprint: A case study of China's South-North Water Diversion Project. Science of the Total Environment, 2016, 545, 601-608.

92. Zou, J.; Zhan, C.; Xie, Z.; Qin, P.; Jiang, S. Climatic impacts of the Middle Route of the South-to-North Water Transfer Project over the Haihe River basin in North China simulated by a regional climate model. Journal of Geophysical Research: Atmospheres, 2016, 121(15), 8983-8999.

93. Chen, F.; Xie, Z. Effects of inter basin water transfer on regional climate: A case study of the Middle Route of the South-to-North Water Transfer Project in China. Journal of Geo-physical Research: Atmospheres, 2010, 115(D11).

94. Liu, Y. Y.; Dorigo, W. A.; Parinussa, R. M.; de Jeu, R. A.; Wagner, W.; McCabe, M. F.; Van Dijk, A. I. J. M. Trend-preserving blending of passive and active microwave soil moisture retrievals. Remote Sensing of Environment, 2012, 123, $280-297$.

95. Li, J. D. Conversion between observed values of soil relative humidity and soil volumetric water content in China. People's Pearl River, 2020,41(6):105-110.(in Chinese)

96. Han, G. Z,; Wang, D. C.; Xie, X. J. Soil bulk density transfer function of main soil types in China. Acta Pedologica Sinica, 2016, 53(1):93-102.(in Chinese)

97. Wu, Z.; Huang, N. E. Ensemble empirical mode decomposition: a noise-assisted data analysis method. Advances in adaptive data analysis, 2009, 1(1), 1-41.

98. Lu, C. W.The characteristics of multi-scale periodic fluctuations in the Shanghai real estate market-analysis based on ensemble empirical mode decomposition and periodic phase identification.Shanghai Economic Research, 2020,8, 46-57.(in Chinese)

99. Fu, C. B,; Wang, Q. The definition and detection methods of climate change. Chinese Journal of Atmospheric Sciences, 1992, 4, 482-493.(in Chinese)

100. Xu, J,; Wang, L,; Wang, Y,; Yue, B. J,; Wang, L. Y,; Cao, X. F. Spatio-temporal dynamics of vegetation NDVI in Shendong mining area from 2000 to 2017.Research of Soil and Water Conservation, 2021, 28, 153-158.(in Chinese)

101. Chen, H. X,; Zhong, J. S,; Lan, A.J,; Liu, J,; Zhao, N.P. Analysis of the temporal and spatial changes of NDVI in Guizhou Province based on topographic and geomorphological factors. Guizhou Science, 2019, 37, 36-43.(in Chinese)

102. Shellito, P. J.; Small, E. E.; Colliander, A.; Bindlish, R.; Cosh, M. H.; Berg, A. A.; Walker, J. P. SMAP soil moisture drying more rapid than observed in situ following rainfall events. Geophysical Research Letters, 2016, 43, 8068-8075.

103. Gruber, A.; Su, C. H.; Crow, W. T.; Zwieback, S.; Dorigo, W. A.; Wagner, W. Estimating error cross-correlations in soil moisture data sets using extended collocation analysis. Journal of Geophysical Research: Atmospheres, 2016, 121, $1208-1219$.

104. Liu, K,; Du L. T,; Hou, J.; Hu, Y,; Zhu, Y. G,; Gong, F. Characteristics of temporal and spatial changes of NDVI in China's terrestrial ecosystems in the past 30 years. Acta Ecologica Sinica, 2018, 38, 1885-1896.(in Chinese)

105. Mälicke, M.; Hassler, S. K.; Blume, T.; Weiler, M.; Zehe, E. Soil moisture: variable in space but redundant in time, Hydrol. Earth Syst. Sci., 2020, 24, 2633-2653.

106. James, S. E.; Pärtel, M.; Wilson, S. D.;, Peltzer, D. A. Temporal heterogeneity of soil moisture in grassland and forest. Journal of Ecology, 2003, 234-239. 
107. Gwak, Y.; Kim, S. Factors affecting soil moisture spatial variability for a humid forest hillslope. Hydrological Processes, 2017, 31, 431-445.

108. Kurc, S. A.; Small, E. E. Soil moisture variations and ecosystem-scale fluxes of water and carbon in semiarid grassland and shrubland. Water Resources Research, 2007, 43(6).

109. Gremer, J. R.; Bradford, J. B.; Munson, S. M.; Duniway, M. C. Desert grassland responses to climate and soil moisture suggest divergent vulnerabilities across the southwestern United States. Global Change Biology, 2015, 21, 4049-4062.

110. Chen, X.; Hu, Q. Groundwater influences on soil moisture and surface evaporation. Journal of Hydrology, 2004, 297, 285-300.

111. Vreugdenhil, M.; Dorigo, W. A.; Wagner, W.; De Jeu, R. A.; Hahn, S.; Van Marle, M. J. Analyzing the vegetation parameterization in the TU-Wien ASCAT soil moisture retrieval. IEEE Transactions on Geoscience and Remote Sensing, 2016, 54, 3513-3531.

112. Henry, J. A.; Dicks, S. E.; Marotz, G. A. Urban and rural humidity distributions: Relationships to surface materials and land use. Journal of Climatology, 1985, 5, 53-62.

113. Cho, E.; Choi, M. Regional scale spatio-temporal variability of soil moisture and its relationship with meteorological factors over the Korean peninsula. Journal of Hydrology, 2014, 516, 317-329. 